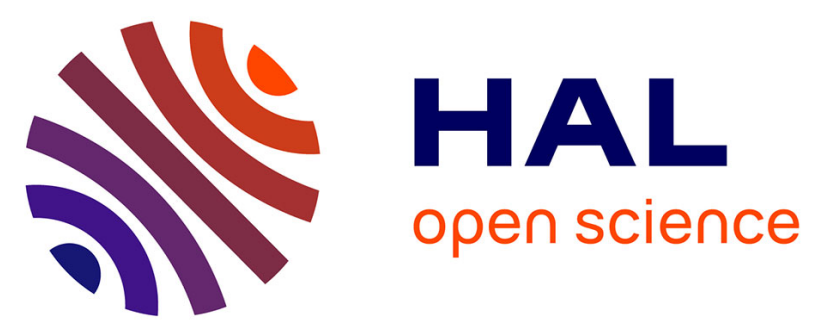

\title{
Synthesis and characterization of p-xylylenediaminium bis(nitrate). Effects of the coordination modes of nitrate groups on their structural and vibrational properties
} S. Gatfaoui, N. Issaoui, Silvia Antonia Brandán, Thierry Roisnel, H. Marouani

\section{- To cite this version:}

S. Gatfaoui, N. Issaoui, Silvia Antonia Brandán, Thierry Roisnel, H. Marouani. Synthesis and characterization of p-xylylenediaminium bis(nitrate). Effects of the coordination modes of nitrate groups on their structural and vibrational properties. Journal of Molecular Structure, 2018, 1151, pp.152-168. 10.1016/j.molstruc.2017.09.027 . hal-01619416

HAL Id: hal-01619416

https://hal-univ-rennes1.archives-ouvertes.fr/hal-01619416

Submitted on 12 Dec 2017

HAL is a multi-disciplinary open access archive for the deposit and dissemination of scientific research documents, whether they are published or not. The documents may come from teaching and research institutions in France or abroad, or from public or private research centers.
L'archive ouverte pluridisciplinaire HAL, est destinée au dépôt et à la diffusion de documents scientifiques de niveau recherche, publiés ou non, émanant des établissements d'enseignement et de recherche français ou étrangers, des laboratoires publics ou privés. 


\section{ACCEPTED MANUSCRIPT}

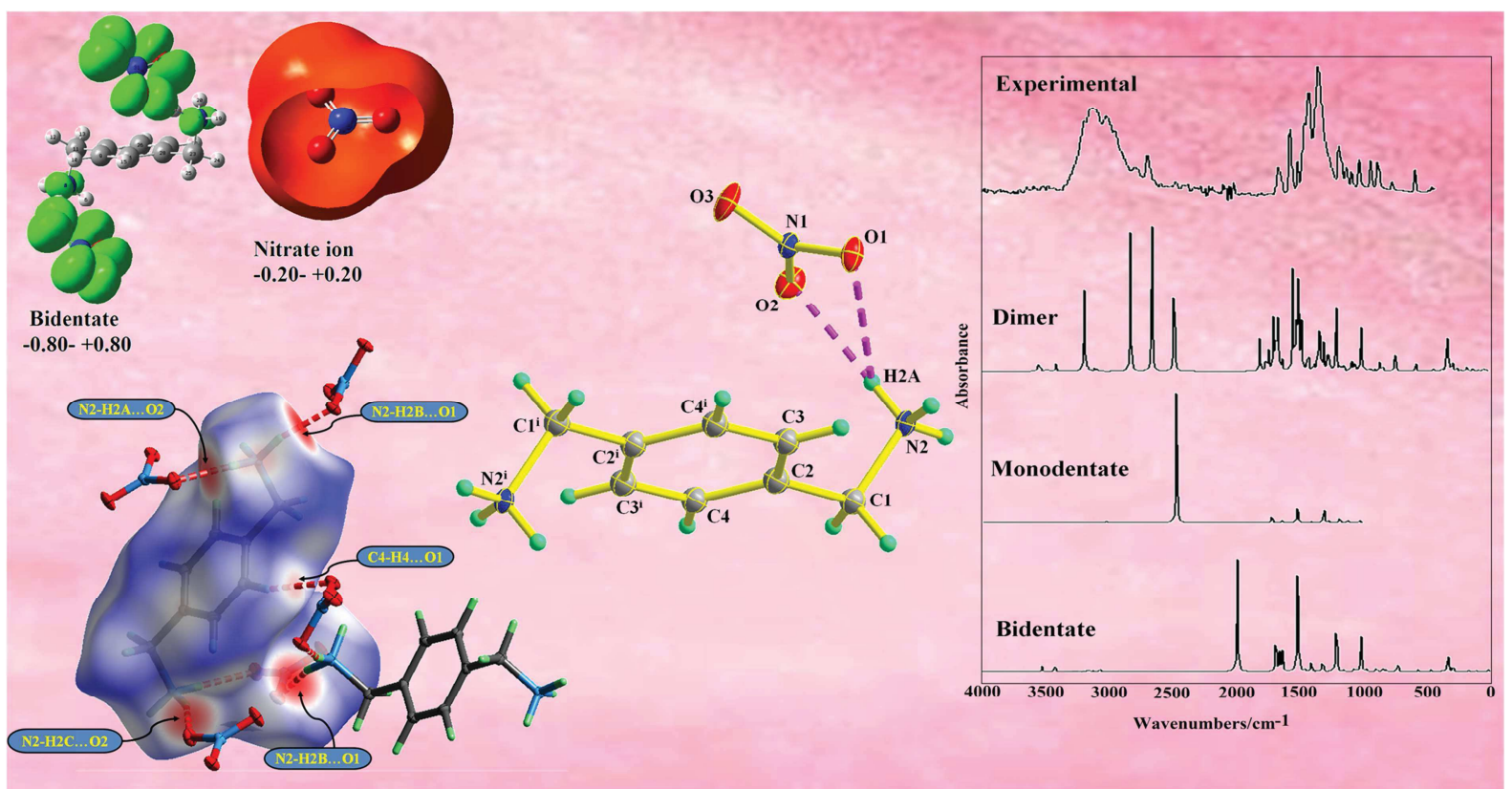


Synthesis and Characterization of p-Xylylenediaminium bis(nitrate).

Effects of the Coordination Modes of Nitrate Groups on Their Structural and Vibrational properties

\author{
S. Gatfaoui ${ }^{\mathrm{a}}$, N. Issaoui ${ }^{\mathrm{b}}$, Silvia A. Brandán ${ }^{\mathrm{c},},{ }^{*}$, T. Roisnel ${ }^{\mathrm{d}}$, H. Marouani $^{\mathrm{a}}$ \\ ${ }^{a}$ Laboratoire de chimie des matériaux, Faculté des Sciences de Bizerte, Université de \\ Carthage, 7021 Zarzouna, Tunisia \\ ${ }^{b}$ Quantum Physics Laboratory, Faculty of Sciences, University of Monastir, Monastir, \\ 5079, Tunisia. \\ ${ }^{c}$ Cátedra de Química General. Instituto de Química Inorgánica. Facultad de \\ Bioquímica, Química y Farmacia. Universidad Nacional de Tucumán. Ayacucho 471. \\ 4000. San Miguel de Tucumán. Tucumán. R. Argentina. \\ ${ }^{d}$ Centre de Diffractométrie X, UMR 6226 CNRS, Unité Sciences Chimiques de Rennes, \\ Université de Rennes I, 263 Avenue du Général Leclerc, 35042 Rennes, France
}

\begin{abstract}
The p-xylylenediaminium bis(nitrate) compound have been synthesized and then, it was characterized by using Fourier Transform infrared (FT-IR) in the solid phase and, by using the Ultraviolet-Visible (UV-Visible) and Hydrogen and Carbon Nuclear Magnetic Resonance $\left({ }^{1} \mathrm{H}\right.$ - and $\left.{ }^{13} \mathrm{C}-\mathrm{NMR}\right)$ spectra in aqueous solution and in dimethylsulfoxide solvent. In this work, two monodentate and bidentate coordination modes were considered for the nitrate ligands in both media in order to study the structural and vibrational properties of that salt. Hence, the natural bond orbital (NBO), atoms in molecules (AIM), Merz-Kollman (MK) charges, molecular electrostatic potentials (MEP) and frontier orbitals studies were performed for p-xylylenediaminium bis(nitrate) and their cation and anion species taking into account for the salt those two coordination modes for the nitrate ligands. The intermolecular interactions of this salt were also evaluated by Hirshfeld surface analysis. The B3LYP calculations performed by using the hybrid method and the $6-311 \mathrm{G}^{*}$ and $6-311++\mathrm{G}^{* *}$ basis sets generate monodentate and bidentate structures with $C_{i}$ and $C_{2}$ symmetries, respectively. The force fields and the force constants values for these two structures were also computed and their complete vibrational assignments were performed by using those both levels of theory. The strong band at $1536 \mathrm{~cm}^{-1}$, the bands between 2754 and $2547 \mathrm{~cm}^{-1}$ and the bands between 1779 and $1704 \mathrm{~cm}^{-1}$ support clearly the presence of the dimeric species while the IR bands at $1986 / 1856 \mathrm{~cm}^{-1}$ could justify the presence of the bidentate species in the solid phase.
\end{abstract}

Keywords: p-Xylylenediaminium bis(nitrate), vibrational spectra, molecular structure, force field, DFT calculations.

\footnotetext{
${ }^{*}$ Corresponding author

E-mail address: sbrandan@fbqf.unt.edu.ar (S.A. Brandán).

Tel.: +543814247752; fax: +543814248169.
} 


\section{Introduction}

The nitrate compounds and their structural and vibrational properties are very attractive to study from different points of view because the coordination modes of these groups have influence on their reactivities and on the stereochemistry of these compounds [14]. Thus, they can be used in multiple applications such as precursors catalytic of numerous reactions, in biological treatment systems or as pharmacological products [15]. In this latter case, it is very important to know the pharmacokinetics and the mechanisms of action of nitrates groups because when they are employed in pharmacy, as in the glyceryl trinitrate case, their measurement of plasma concentrations are very difficult, as mentioned by Bogaert [6]. On the other hand, in inorganic compounds where these groups are linked to transitions metals, two monodentate or bidentate coordination modes can be observed in these nitrate ligands when two or three charges are present on the metal. For instance, in chromyl, vanadyl or niobyl nitrates those two coordination modes were observed on the $\mathrm{CrO}_{2}{ }^{2+}, \mathrm{VO}^{3+}$ and $\mathrm{NbO}^{3+}$ groups, respectively $[1,2,4]$. Many organic nitrate esters, such as Glyceryl trinitrate, isosorbide dinitrate, and isosorbide-5-mononitrate are generally used in the treatment of angina pectoris, myocardial infarction, and congestive heart failure, as reported by Torfgård and Ahlner [5]. For all these reasons, their structural studies are of interest as well chemical as biologically. In this work, we have synthesized and studied p-xylylenediaminium bis(nitrate), an organic compound containing a p-xylylene $\mathrm{C}_{6} \mathrm{H}_{4}\left(\mathrm{CH}_{2}\right)_{2}$ group in their structure where each $\mathrm{CH}_{2}$ group is linked to a $\mathrm{NH}_{3}{ }^{+}$group which are connected to $\mathrm{NO}_{3}{ }^{-}$ groups. Chemically, the p-xylylene groups undergoes rapid polymerization to poly-pxylylene and, for this reason, it is particularly interesting to also evaluate their properties from this point of view. In particular, when the p-xylylenediaminium structure is present in a compound interesting structural and biological properties were found [7-10]. So far, only the structure for m-xylylenediaminium dinitrate was reported where the two nitrate groups are in meta positions in relation to the benzene ring [8]. Here, the two nitrate groups are in para positions and, for this reason, changes in their properties are expected for this compound. The experimental infrared spectrum of $\mathrm{p}$ xylylenediaminium bis(nitrate) in the solid phase and the UV-Visible and ${ }^{1} \mathrm{H}-$ and ${ }^{13} \mathrm{C}$ NMR spectra in aqueous and dimethylsulfoxide solutions were combined with theoretical calculations derived from the density functional theory (DFT) in order to study the structures of p-xylylenediaminium bis(nitrate) taking into account the two monodentate and bidentate coordination modes of the nitrate groups. At this point, the 
hybrid B3LYP method with the 6-311G* and 6-311++G** basis sets $[11,12]$ were used to perform the calculations of their charges, bond orders, molecular electrostatic potential, donor-acceptor energy interaction, topological properties and frontier orbitals. Similar calculations were also performed to the p-xylylenediaminium cation and to the nitrate anion in order to compare the influence of both on the properties of the salt. In addition, their force fields for the isolated molecule considering monodentate and bidentate coordination modes were performed with the scaled quantum mechanical force field (SQMFF) methodology and the Molvib program $[13,14]$. Then, the complete assignments of the 90 vibration normal modes were performed for those two coordination modes. Here, the force constants for the nitrate and ammonium groups were compared with other reported for similar molecules [1-4].

\section{Experimental methods}

\subsection{Preparation of $\mathrm{C}_{8} \mathrm{H}_{14} \mathrm{~N}_{2}\left(\mathrm{NO}_{3}\right)_{2}$ (PXDAN)}

The organic-inorganic hybrid material $\mathrm{C}_{8} \mathrm{H}_{14} \mathrm{~N}_{2}\left(\mathrm{NO}_{3}\right)_{2}$ was synthesized by the reaction containing $1 \mathrm{mmol}$ of $\mathrm{p}$-Xylylenediamine dissolved in $10 \mathrm{~mL}$ of water and $2 \mathrm{mmol}$ of Nitric acid in $10 \mathrm{~mL}$ of water. The resulting solution was stirred for $2 \mathrm{hrs}$, filtered and then left to stand at room temperature. Colorless crystals of very high quality were obtained after 10 days with a slow evaporation. A single crystal suitable for X-ray diffraction analysis was selected and studied. Schematically the reaction can be written:

\section{$\mathrm{C}_{8} \mathrm{H}_{12} \mathrm{~N}_{2}+2 \mathrm{HNO}_{3} \stackrel{\mathrm{T}=25^{\circ} \mathrm{C}}{\longrightarrow} \mathrm{C}_{8} \mathrm{H}_{14} \mathrm{~N}_{2}\left(\mathrm{NO}_{3}\right)_{2}$}

\subsection{Characterization}

The p-xylylenediaminium bis(nitrate) compound was characterized in the solid state by using the FT-IR spectrum while the ultraviolet-visible spectra and ${ }^{1} \mathrm{H}-$ and ${ }^{13} \mathrm{C}-\mathrm{NMR}$ spectra were recorded in aqueous and dimetilsolfoxide solutions.

3. Computational details The intensity data were collected at $150 \mathrm{~K}$ using a diffractometer Bruker-AXS D8 VENTURE, with MoK $\alpha$ radiation $(\lambda=0.71073 \AA)$. Absorption corrections were performed using the multi-scan technique using the SADABS program [15]. The total number of measured reflections was 5946 among which 1312 were independent and 1221 had intensity $I>2 \sigma(I)$. The structure was solved by direct methods using the SIR97 program [16] and then refined with fullmatrix least-square methods based on $F^{2}$ (SHELXL-97) [17] with the aid of the WINGX 
program [18]. All non-hydrogen atoms were refined with anisotropic atomic displacement parameters. All the hydrogen atoms were placed in calculated positions and refined with fixed individual displacement parameters $\left[\mathrm{U}_{\mathrm{iso}}(\mathrm{H})=1.2 U_{\mathrm{eq}}(\mathrm{C})\right.$ and $\left.\mathrm{U}_{\text {iso }}(\mathrm{H})=1.5 U_{\text {eq }}(\mathrm{N})\right]$ according to the riding model $(\mathrm{N}-\mathrm{H}$ bond lengths of $0.89 \AA$, and $\mathrm{C}-\mathrm{H}$ (aromatic, methylene) bond lengths of $0.93 \AA$ and $0.97 \AA$, respectively).

A final refinement on $F^{2}$ converged at $R\left(F^{2}\right)=0.030$ and $\mathrm{w} R\left(F^{2}\right)=0.082$. The parameters used for the X-ray data collection as well as the strategy for the crystal structure determination and its final results are reported in Table 1. An ORTEP [18] drawing of the molecular structure is shown in Fig. 1a.

Supporting information (CIF files) can be obtained from the CCDC database free-of charge via http://www.ccdc.cam.ac.uk/structure-summary-form quoting the CCDC reference number CCDC-1553215 or from the Cambridge Crystallographic Data Centre, 12 Union Road, Cambridge CB21EZ, UK; or by email to deposit@ccdc.cam.ac.uk.

The theoretical initial structure of p-xylylenediaminium bis(nitrate) (PXDAN) was similar to that experimentally determined by X-ray diffraction where monodentate and bidentate coordinations were observed for both nitrate groups. Then, other theoretical pxylylenediaminium bis(nitrate) structure was proposed which was modelled by using the GaussView program [19] where the two nitrate groups have bidentate coordination modes. Those two different structures were later optimized by using the hybrid B3LYP method and the $6-311 \mathrm{G}^{*}$ and $6-311++\mathrm{G}^{* *}$ basis sets with the Gaussian 09 program [20]. Both structures with the nitrate ligands with monodentate and bidentate coordination modes can be seen in Figures $\mathbf{2}$ and 3, respectively. The ionic interactions expected for both nitrate groups were evaluated by using the Mulliken, the atomic natural population (NPA) and the Merz-Kollman (MK) charges [21] because with it latter charge it is possible to compute the corresponding molecular electrostatic potential. The intermolecular interactions were also studied by Hirshfeld surface analysis which was carried out using the Crystal Explorer 3.1 software [22] imported on a CIF file. In this study, NBO calculations [23] were used to calculate the donoracceptor energy interactions while the topological properties were determined with the AIM2000 program [24] in accordance with the Bader's theory [25]. These calculations were performed in gas phase by using the Gaussian 09 program [20].

The SQMFF procedure [13] and the Molvib program [14] were also used to compute the force fields for the two coordination modes taking into account their corresponding 
normal internal coordinates and potential energy distribution (PED) contributions $\geq$ $10 \%$. Besides, the dimer of $\mathrm{p}$-xylylenediaminium bis(nitrate) was also considered because many bands observed in the experimental infrared spectrum are also justified with bands related to this species. The dimeric species optimized by using the B3LYP/6-311+G* method present the two coordination modes, as shown in Figure 4. Here, it is necessary to clarify that the internal coordinates for both coordination modes of the nitrate groups were similar to those reported for other nitrate compounds [1-4] while the corresponding to the ring are very simple and are widely known [26-28] and, for these reasons, they were not presented in this work.

The predicted ultraviolet-visible spectrum for this nitrate compound with both monodentate and bidentate structures were also predicted in aqueous solution and, in the dimethylsulfoxide solvent by using Time-dependent DFT calculations (TD-DFT) at the 6-311++ $\mathrm{G}^{* *}$ and $6-311 \mathrm{G}^{*}$ levels of theory, respectively with the Gaussian 09 program [20]. The optimizations of p-xylylenediaminium bis(nitrate) in these two solvents were performed by using the self consistent force field (SCRF) calculations with the PCM and SM models [29-31]. The volume variations that experiment $p$-xylylenediaminium bis(nitrate) in both solvents were computed with the Moldraw program [32]. The solvation energies predicted for PXDAN were also reported taking into account the two coordination modes expected for the nitrate ligands. On the other side, the reactivities and the behaviors of the salt and their cation and anion species in aqueous solution and in DMSO solvent were also predicted by using the frontier orbitals [33,34] together with well-known descriptors in order to observe the effects of both ions on the salt properties [26-28,35].

\section{Results and discussion}

\subsection{X-ray diffraction}

The asymmetric unit of the title salt, $\mathrm{C}_{8} \mathrm{H}_{14} \mathrm{~N}_{2}{ }^{2+} .2 \mathrm{NO}_{3}{ }^{-}$contains one nitrate anion and a half of p-xylylenedaminium cation (Fig. 1a), the complete dication is generated by crystallographic inversion symmetry. Bond distances and bond angles of PXDAN are listed in (Table 3).

The structure is characterized by infinite sheets shaped by $\mathrm{p}$-xylylenediaminium cations and nitrate anions through hydrogen bond types N-H...O and C-H...O. These sheets are parallel to the $a b$ plane at $z=1 / 4$ and $3 / 4$, which are linked to a further by additional hydrogen bonds along the $c$-axis, therefore forming the three dimensional infinite network (Fig. 1b). 
Inside this arrangement, all atoms in the nitrate anion are coplanar with the bond distances for O-N varying between 1.2341(11) and 1.2670(11) A. The O-N-O angles were in the range of $118.23(8)-121.11(8)^{\circ}$. These bond lengths and angles are in good agreement with those observed in similar compounds $[8,36]$.

Assessment of the organic geometrical features (Table 3) shows that the pxylylenediaminium cation exhibits a normal spatial configuration with $\mathrm{C}-\mathrm{C}$ and $\mathrm{N}-\mathrm{C}$ distances and C-C-C, N-C-C, C-N-C and C-C-C angles quite similar to those found in xylylenediamine derivatives $[8,10]$.

Both ammonium groups in organic cation adopt a trans conformation with respect to the benzene ring. The same conformation has been observed in other compound associated to the identical organic cation [37].

All the hydrogen atoms bonded to the amine group of p-xylylenediaminium dication contribute to the formation of $\mathrm{N}-\mathrm{H}$... O hydrogen bonding pattern with nitrate anions (Table 2). Organic cations are also connected together via $\mathrm{C}-\mathrm{H} \ldots \pi$ interactions forming subsequently infinite chains spreading along the a-axis (Fig. 1c).

$\mathrm{H}$ bonds $(\mathrm{N}-\mathrm{H} . . \mathrm{O})$, weak interactions $(\mathrm{C}-\mathrm{H} \ldots \mathrm{O}$ and $\mathrm{C}-\mathrm{H} \ldots \pi)$, and van der Waals contacts give rise to a three-dimensional network in the structure and add steadiness to this compound.

\subsection{Structural study in gas and in solution phases}

The theoretical p-xylylenediaminium bis(nitrate) structure is completely symmetrical and it was optimized by using B3LYP/6-311G* and $6-311++\mathrm{G}^{* *}$ calculations with $C_{i}$ symmetry and null dipole moment and, where monodentate coordination modes are observed in the two nitrate groups. Besides, the $\mathrm{NH}_{3}{ }^{+}$groups have practically tetrahedral bond angles while the bonds N-H linked to the nitrate groups are longer than the other ones, as observed in Figure 2. On the other hand, the other theoretical proposed PXDAN structure with bidentate coordination modes was optimized with $C_{2}$ symmetry and with imaginary frequencies by using $6-31 \mathrm{G}^{*}$ and $6-311++\mathrm{G}^{* *}$ basis sets while when the calculations were performed by using the $3-21 \mathrm{G}^{*}$ and $6-311 \mathrm{G}^{*}$ basis sets all frequencies were positive, indicating the possible existence of this structure in gas phase and/or in solution. Here, this structure was also considered in this study because the calculations with bidentate coordination modes in solution generate positive frequencies. Obviously, for the bidentate structures all calculations were performed by using the $6-311 \mathrm{G}^{*}$ basis set because this level generate the most stable structure, as revealed by the results presented in Table $\mathbf{S 1}$ (supporting material). These results show 
that the monodentate species have dipole moment null in gas phase by using two levels of theory but, in aqueous solution the value increase up to $2.58 \mathrm{D}$ while the bidentate form present higher dipole moment values especially in solution, having their higher value in water. Note that the monodentate form is practically most voluminous than the other one and present the higher volume expansion in DMSO. In this work, the cationic, anionic and p-xylylenediamine base of PXDAN were also modeled and optimized in all media by using the longer size basis set. These calculations clearly show that the nitrate anion has a low volume value in aqueous solution but it anion presents the higher volume variations, as expected because it ion is soluble in this medium. On the contrary, the $\mathrm{p}$-xylylenediaminium cation presents the lower volume variations in the two media and, also the more low values. On the other hand, those three species have null dipole moments in the three different studied media.

The predicted corrected solvation energies PXDAN for all species studied by using the 6-311++G** basis set and considering both monodentate and bidentate coordination modes for the nitrate groups can be seen in Table S2. These values were computed from the differences between the uncorrected values and the non-electrostatic terms $\left(\Delta \mathrm{G}_{\mathrm{c}}=\Delta \mathrm{G}_{\mathrm{un}}-\Delta \mathrm{G}_{\mathrm{ne}}\right)$ calculated from the universal SM calculations [31]. When the solvation energies are in detail analyzed we observed that the cationic species present higher values in solution than the other ones probably because it is a double charged species while the values for the nitrate anion are closer to the corresponding to the salt in water. Obviously, we expected that the charged ionic species are most hydrated in both solvents and, for these reasons, they have the higher values. Hence, the presence of the nitrate groups in PXDAN increases strongly the solubility of the salt, as compared with their p-xylylenediamine base while the presences of two additional $2 \mathrm{H}^{+}$in the base increase significantly the solvation energy of the cation in water from $-47.67 \mathrm{~kJ} / \mathrm{mol}$ in the base up to $-821.55 \mathrm{~kJ} / \mathrm{mol}$ in the cationic form.

The theoretical parameters for those two coordination modes are compared in Table 3 with the corresponding experimental ones by using the root mean square deviation (RMSD) values while in Table 4 are presented the parameters for PXDAN in aqueous solution and in dimethylsulfoxide solvent. The calculations show that both ammonium groups in each cation present trans conformation with respect to the benzene ring, as was experimentally observed in similar studies [7-10]. The calculated bond lengths show a better concordance with the experimental ones than the bond angles with values between 1.015 and $0.884 \AA$ in gas phase while in solution increase between 1.120 and 
$0.965 \AA$ A. The bond lengths variations in all media can be seen in Figure S1 for the two monodentate and bidentate structures at different levels of theory. Analyzing first for the monodentate species, it is possible to observe: (i) similar bond lengths in both nitrate and amonium groups, as expected because this species is symmetrical having in water the longer $\mathrm{N}-\mathrm{H}$ bonds due to that these bonds are linked to the nitrate groups, (ii) the N$\mathrm{O}$ bonds have approximately the same values than the experimental ones, (iii) only two $\mathrm{N}-\mathrm{H}$ bonds of the three belong to the $\mathrm{NH}_{3}{ }^{+}$groups in water and in dimethylsulfoxide present identical values but very different from the values in gas phase. Hence, the N5H6 and N17-H18 bonds in gas phase have values very different from the experimental ones probably because the existences of these nitrato and amonium ions are observed only in solution. In relation to the $\mathrm{C}-\mathrm{C}$ bonds belong to the ring, all them have practically the same values with exception of the C26-C21 bond that shows a low values in water. The O1-H6 and O29-H18 distances are similar in solution but very different to the experimental values and to those observed in gas phase, showing in this medium the lowest values. On the other side, the N5-C11, N17-C23, C11-C16 and C23C28 bonds present the same values in all media and are in agreement with the experimental ones. When the bond lengths are analyzed for the bidentate species in all media, it is possible to observe very different behaviours than the structures with monodentate coordination modes and, in this case, all the bonds lengths have practically the same values than the experimental ones with exception of the O1-H6 and O29-H18 distances which have different values in the three media. Therefore, the O1-H6 bonds are similar in solution but the O29-H18 distances values in gas phase are closer to the experimental ones. In this structure, all the $\mathrm{C}-\mathrm{C}$ bonds are predicted in accordance with the experimental values. The similarities observed between the predicted distances for the bidentate coordination with the experimental ones suggest the existence of this form in the solid phase.

Analyzing the bond angles of both structures from Figure S2 whose values are presented in Tables 3 and 4, we observed similar behaviours of all angles for the monodentate and bidentate coordination modes but different from the two N-H-O angles. Thus, in the monodentate form the N5-H6-O1 and N7-H8-O29 angles are approximately similar in the three media but only the N7-H8-O29 angles are in agreement with the experimental ones. A similar behaviour it is observed in the bidentate structure but, in this case the N5-H6-O1 angles in water is different than the observed in DMSO and only the value in gas phase is closer to the experimental one. 
Here, the existence of the bidentate species in the solid state is supported by the concordance of practically all analyzed bond angles and by the low RMSD values calculated for these coordination modes, as indicated in Tables 3 and 4.

In relation to the dihedral angles, both coordination modes show different behaviours in the three media, as observed in Figure S3. For the monodentate coordination, we observed a similar behaviour in gas phase and in water while for the bidentate species the angles in water and in DMSO solution show a reasonable concordance. The dihedral C16-C11-N5-H6 and O32-N31-O29-H18 angles in the monodentate structure in all media are in very good concordance but, in the bidentate coordination modes only are in agreement the values of those angles calculated in gas phase and in DMSO solution. The similarities in the bond lengths and angles calculated for both coordination modes together with the presence of both modes in the dimeric species clearly support the existence of those two coordination modes for the nitrate groups in the salt in the solid phase and, for these reasons, both structures can be used to perform the vibrational analysis.

\subsection{Charges, molecular electrostatic potentials (MEP) and bond orders (BO)}

The atomic Mulliken, MK and NPA charges, molecular electrostatic potentials and bond orders expressed as Wiberg indexes for PXDAN calculated by using the hybrid B3LYP/6-311++G** level of theory are observed for the monodentate case in Table S3 while for the bidentate coordination it is observed in Table S4. Note that in this latter case, for the bidentate coordination in water the calculation produces imaginary frequencies and, for this reason, the values are not presented here. Figure S4 shows the variations of those three charges on all atoms belong to the $\mathrm{NO}_{3}{ }^{-}$and $\mathrm{NH}_{3}{ }^{+}$groups of PXDAN calculated in gas phase at the same level of theory. We presented only the values in gas phase because the behaviors in water and in DMSO are practically the same. Both graphics show that the behaviors of those three charges on the atoms corresponding to the two $\mathrm{NO}_{3}{ }^{-}$and $\mathrm{NH}_{3}{ }^{+}$groups symmetrical present the same values. This way, the MK and NPA charges predict approximately the same values for the $\mathrm{O}$ atoms of both $\mathrm{NO}_{3}{ }^{-}$groups but the Mulliken charges on the $\mathrm{N} 3$ and $\mathrm{N} 31$ atoms exhibit negative signs instead positive as observed with the MK and NPA charges. In relation to the $\mathrm{NH}_{3}{ }^{+}$groups, we observed that the $\mathrm{H} 7, \mathrm{H} 8, \mathrm{H} 19$ and $\mathrm{H} 20$ have practically the same charges being slightly higher the NPA ones. The positive higher values are observed on the H6 and H18 atoms but the MK charges show lower values than the other ones. On the contrary, the MK charges on the N5 and N17 atoms exhibit the less negative values 
than the other ones. When those three charges on the $\mathrm{C}$ and $\mathrm{H}$ atoms of PXDAN are analyzed in Figure S5, we observed that their variations follow approximately the same tendency where, the MK and NPA charges show the same behaviors, different from the Mulliken ones. Hence, only on the two C16 and C28 atoms are observed positive Mulliken charges while the most negative values are predicted on the C11 and C23 atoms belong to the $\mathrm{CH}_{2}$ groups.

Regarding the molecular electrostatic potentials values presented in Table S5 together with the bond order values, we observed similar values on all atoms belong to the $\mathrm{NO}_{3}{ }^{-}$ and $\mathrm{NH}_{3}{ }^{+}$groups where the most negative values are observed on the $\mathrm{O} 2, \mathrm{O} 4, \mathrm{O} 30$ and O32 atoms linked to the $\mathrm{N} 3$ and $\mathrm{N} 31$ atoms forming $\mathrm{N}=\mathrm{O}$ bonds in the $\mathrm{NO}_{3}{ }^{-}$groups while the less negative values are observed on the H6 and H18 atoms forming monodentate coordinations with the nitrate groups. Hence, those two regions are easily identified by these values as nucleophilic and electrophilic sites. Here, the MEP surface mapped for the monodentate coordination was not possible to determine but Figure S6 shows the MEP surface mapped for the bidentate coordination of PXDAN calculated in gas phase at the B3LYP/6-311G* level of theory together with the MEP surface mapped for the nitrate ion. Obviously, the ion presents a strong red color on the entire surface, as expected because it is a negative ion while when these groups have bidentate coordination to the p-xylylenediaminium cation in PXDAN in gas phase green colorations are observed on these two groups. Here, that green colour could probably be justified because the calculations were performed in gas phase while in solution these groups are as ions.

Analyzing the bond order values from Table S5 for all atoms belong to both coordination modes, evidently both $\mathrm{NO}_{3}{ }^{-}$and $\mathrm{NH}_{3}{ }^{+}$groups also have the same values because both groups are symmetrical, as observed in the three charges values. Here, the monodentate coordination in gas phase present higher values that the other coordination mode in the same medium but, in solution the values for the $\mathrm{O}$ atoms decrease while for the $\mathrm{N}$ atoms slightly increase. In general, lower $\mathrm{BO}$ values are observed in the $\mathrm{O} 1$ and O29 because they are linked to the H6 and H18 atoms, respectively and, where these atoms also present the lowest values.

\subsection{Study of intermolecular interactions by Hirshfeld surface analysis}

The embedding and crystalline architecture of synthesized material were evaluated by Hirshfeld surface analysis [22]. This analysis provides the opportunity to obtain a quantitative overview of contacts and intermolecular interactions and illustrated on 
fingerprint maps (2D). The Figure 5 shows the views of Hirshfeld surfaces mapped with $d_{\text {norm }}$, Shape index and curvedness properties of the $\mathrm{C}_{8} \mathrm{H}_{14} \mathrm{~N}_{2}\left(\mathrm{NO}_{3}\right)_{2}$ (PXDAN) compound. The expression of the normalized contact distance $\left(d_{\text {norm }}\right)$ based on both $d_{e}$, $d_{i}$ and the vdw radii of the atom, is given by the following formula:

$$
d_{\text {norm }}=\frac{d_{i}-r_{i}^{v d W}}{r_{i}^{v d W}}+\frac{d_{\varepsilon}-r_{\varepsilon}^{v d W}}{r_{\varepsilon}^{v d W}}
$$

With $d_{e}$ is the distance from the point to the nearest atom outside to the surface, $d_{i}$ is the distance to the nearest atom inside to the surface, $r_{i}^{v d W}$ and $r^{v d W}$ indicates the van der Waals radii of the appropriate atoms internal and external to the surface, respectively. The normalized contact distance $\left(d_{\text {norm }}\right)$ (Fig. 5a) makes it possible to graphically illustrate the relative positioning of neighboring atoms belonging to molecules interacting together. This graph type displays a surface with a color scheme (red, blue and white) where the red spots show the shortest intermolecular contacts less than the sum of the van der Waals rays attributed to the hydrogen bonds of types N-H ... O (large dark red spot) and $\mathrm{C}-\mathrm{H} \ldots \mathrm{O}$ (small light red spot). The blue zones indicate the longest intermolecular contacts greater than the sum of the van der Waals rays, and the white regions represent the contacts around the van der Waals separation. These two lines correspond respectively to the intercontacts $\mathrm{H} \ldots \mathrm{H}$ and $\mathrm{C} \ldots \mathrm{H} / \mathrm{H}$... C [38]. The shape index (Fig. 5b) and curvedness (Fig. 5c) maps can be also used to identify the characteristic packaging patterns existing in the crystal. The absence of the red and blue triangles on the Shape index and the small flat segments delineated by blue contours on the curvedness mapping exclude the presence of $\pi-\pi$ interactions in our crystal structure [39]. Quantitative measurements such as molecular volume, surface area, globularity and asphericity were also calculated using Crystal Explorer 3.1 and collected in Table 5. Note that the term of globularity [40] (0.781) is less than unity this implying a more structured molecular surface. In addition, asphericity (0.098) [41,42] is a measure of anisotropy which adopts a very low value indicating the instability of our material. The overall two-dimensional fingerprint (FP) plot, Fig. 6a, and those delineated into, $\mathrm{O} \ldots \mathrm{H} / \mathrm{H} \ldots \mathrm{O}, \mathrm{H} \ldots \mathrm{H}$ and $\mathrm{C} \ldots \mathrm{H} / \mathrm{H} \ldots \mathrm{C}$ contacts are shown in Fig. 6c-e, the relative contributions are summarized in Figure $\mathbf{6 b}$. The distribution of the fingerprint plots (2D) of the PXDAN compound shows that the intermolecular contacts $\mathrm{O} \ldots \mathrm{H} / \mathrm{H} \ldots \mathrm{O}$ (Fig. 6c) occupy the major part of the Hirshfeld surface (60.4\%) and appear in the form of two symmetric wings with an important long tip of sum $\left(d_{e}+d_{i} \sim 1.8 \AA\right)$ less than the sum of the van der Waals radii of the hydrogen $(1.09 \AA)$ and oxygen $(1.52 \AA)$ atoms. 
The H ... H contacts (Fig. 6d) represent almost a quarter $(23.7 \%)$ of the total Hirshfeld surface, these contacts are presented on the fingerprint plot as a distinct point with $\left(d_{i}=\right.$ $d_{e}=1.2 \AA$ ). This value is greater than the van der Waals radius of the hydrogen atom $(1.09 \AA)$. The pair of distinct wings at $\left(d_{e}+d_{i} \sim 3.2 \AA\right)$ greater than the sum of the van der Waals radii of the carbon and hydrogen atoms $(2.79 \AA)$ are attributed to C...H/H...C contacts with a $9.2 \%$ participation on the Hirshfeld surface. These data are characteristic of a $\mathrm{C}-\mathrm{H} \ldots \pi$ interaction. Among these contacts only the $\mathrm{O} \ldots \mathrm{H} / \mathrm{H} \ldots \mathrm{O}$ contacts responsible for the hydrogen bonds $\mathrm{N}-\mathrm{H} \ldots \mathrm{O}$ and $\mathrm{C}-\mathrm{H} \ldots \mathrm{O}$ are considered close with a sum $\left(d_{e}+d_{i}\right)$ less than the sum of the radii of van der Waals of involved atoms. The intermolecular interactions present in the studied compound were evaluated using the enrichment ratio (ER). The $\mathrm{ER}_{\mathrm{XY}}$ enrichment ratio of a chemical element pair $(\mathrm{X}, \mathrm{Y})$ is defined as the ratio between the percentage of the actual contacts in the crystal and the theoretical percentage of the random contacts [39]. The list of enrichment ratios (Table 6) shows the $\mathrm{O} \ldots \mathrm{H} / \mathrm{H} \ldots \mathrm{O}\left(\mathrm{ER}_{\mathrm{OH}}=1.54\right)$ contacts which appear to be favored in the crystal package with the formation of hydrogen bonds $\mathrm{N}-\mathrm{H} \ldots \mathrm{O}$ and $\mathrm{C}-\mathrm{H} \ldots \mathrm{O}$. The $\mathrm{H} \ldots$ $\mathrm{H}$ contacts comprise $27.3 \%$ of the Hirshfeld surface, this value is much lower by the calculated value for the random contacts $(35.40 \%)$, so that these contacts adopt an enrichment ratio far from unity $\left(\mathrm{ER}_{\mathrm{HH}}=0.65\right)$ which not follow the Jelsch expectation [43]. The enrichment ratios values of the $\mathrm{N} \ldots \mathrm{C} / \mathrm{C} \ldots \mathrm{N}, \mathrm{O} \ldots \mathrm{C} / \mathrm{C} \ldots \mathrm{O}$ and $\mathrm{O} \ldots \mathrm{O}$ contacts have a low significance because of their small contributions to the Hirshfeld Surface area, except for C ... C $(0.2 \%)$ contacts which have a compatible enrichment ratio $\left(E R_{C C}=0.69\right)$ at a low propensity to the $\pi-\pi$ interactions.

\subsection{NBO and AIM studies}

The study of the stabilities of PXDAN is the particular interest because their theoretical structure is completely symmetrical where the two nitrate groups can have coordination monodentate or bidentate. Hence, the knowledge of the interactions is important in relation to their stabilities in the different media. The NBO and AIM calculations $[23,24]$ were performed for PXDAN taking into account those two possible coordination modes. Tables $\mathbf{S 6}$ and $\mathbf{S 7}$ show the main donor-acceptor energy interactions for monodentate and bidentate coordination modes of both nitrate groups of p-xylylenediaminium bis(nitrate) in all media by using the hybrid B3LYP/6-311++G** and $6-311 \mathrm{G}^{*}$ levels of theory, respectively. Six different interaction types are observed

for PXDAN when the two nitrate groups have monodentate coordination modes but when these groups present bidentate coordination modes the number of interactions 
increase significantly up to ten interactions. The high stability of the monodentate species in all media can be attributed to the $\Delta E T_{L P \rightarrow \sigma^{*}}$ transitions which are observed from the lone pairs of the $\mathrm{O}$ atoms belong to the nitrate groups toward the antiboding orbitals of $\mathrm{N}-\mathrm{O}$ bonds but, in particular, in the gas phase the total energy increase considerably due to the $\Delta E T_{L P \rightarrow L P^{*}}$ transitions which are observed from the lone pairs of the $\mathrm{O}$ or $\mathrm{N}$ atoms belong to the nitrate groups toward the lone pairs of the H6 and H18 atoms belong to the $\mathrm{NH}_{3}$ groups. We observed that these latter interactions contributed in their higher part to the total energy. Table $\mathbf{S 7}$ shows clearly that the bidentate species is most stable than the monodentate one, especially in the DMSO solvent where the $\Delta E T_{\sigma^{*} \rightarrow \sigma^{*}}$ and $\Delta E T_{\pi^{*} \rightarrow \sigma^{*}}$ transitions are the main contributions to the total energy.

The topological properties were calculated considering both coordination modes of PXDAN because these parameters are useful to predict their intra-molecular interactions. The AIM2000 program [24] was used to compute the electron density, $\rho(r)$, the Laplacian values, $\nabla^{2} \rho(r)$, the eigenvalues $(\lambda 1, \lambda 2, \lambda 3)$ of the Hessian matrix and, the $|\lambda 1| / \lambda 3$ ratio calculated in the bond critical points (BCPs), as suggested by Bader [25]. These parameters for both coordination modes of PXDAN in gas phase, aqueous solution and in DMSO solvent are presented respectively in Tables S8 and S9. When the ratio is $|\lambda 1| / \lambda 3<1$ and $\nabla^{2} \rho(r)>0$ the interactions are attributed to $\mathrm{H}$ bonds formations and to the ionic interactions. In this case, the parameters were also computed in the ring critical points (RCPs) of the benzyl ring and, of the new rings formed as a consequence of the new H bonds (RCPN). Table S8 show that the monodentate species is most stable in aqueous solution because five interactions are observed in this medium while in gas phase only four and in DMSO only two interactions are observed. Thus, in the monodentate case, the two $\mathrm{O} 1 \rightarrow \mathrm{H} 6$ and $\mathrm{O} 29 \rightarrow \mathrm{H} 18$ interactions together with the O2---C9 and O30---C21 connections are observed. The bidentate species is clearly most stable than the monodentate ones because in gas phase are predicted a total of six $\mathrm{H}$ bonds interactions while only four interactions are predicted in DMSO solvent. Hence, the $\mathrm{O} 1 \rightarrow \mathrm{H} 6, \mathrm{O} 2 \rightarrow \mathrm{H} 8, \mathrm{O} 29 \rightarrow \mathrm{H} 18, \mathrm{O} 30 \rightarrow \mathrm{H} 20$ interactions together with the $\mathrm{O} 2---\mathrm{C} 9$ and $\mathrm{O} 29---\mathrm{C} 14$ connections give to the bidentate species a great stability in gas phase.

\subsection{HOMO-LUMO and descriptors studies}

When the organic nitrates are employed as a drug it is indispensable to predict the reactivities and behavior in the different media because these parameters can be useful to elucidate the pharmacokinetics and the mechanisms of action of the nitrates groups in 
the different media. In addition, antioxidant, antibacterial and antifungal activities were observed for m-Xylylenediaminium-bis (p-toluenesulfonate) monohydrate [9]. For these reasons, the frontier orbitals and some descriptors [26-228, 33-35] were computed for PXDAN in all studied media considering the two coordination modes of the nitrate groups by using the hybrid B3LYP method. Therefore, Table S10 shows the calculated HOMO and LUMO orbitals, energy band gap, chemical potential $(\mu)$, electronegativity $(\chi)$, global hardness $(\eta)$, global softness $(S)$, global electrophilicity index $(\omega)$ and global nucleophilicity index (E) by using $6-311++\mathrm{G}^{* *}$ basis set for the monodentate coordination while the $6-311 \mathrm{G}^{*}$ basis set was used for the bidentate coordination. The values were compared with those calculated for the p-xylylenediaminium and nitrate ions in the three studied media and with those parameters reported for antimicrobial agents such as the two 1,3-benzothiazole tautomers, thione and thiol [44], for antiviral agents such as, thymidine [45] and, for toxic species such as the $\mathrm{CN}^{-}, \mathrm{CO}$ and saxitoxin [35]. Analyzing in detail the gap results we observed that despite the bidentate form has a higher stability, as supported by NBO and AIM studies, the monodentate form present lower reactivity in the three media because the gap values in gas and DMSO solvent are slightly higher than the corresponding to the bidentate form. When the gap values for the two ions are evaluated we observed that the p-xylylenediaminium cation present higher values in the three media than the nitrate anion. Hence, these values show clearly that the ions are less reactive than PXDAN in gas and aqueous solution while when these values are compared with parameters reported for those species with different activities, we observed that the gap calculated for the monodentate form in gas phase is comparable to the value observed for thymidine [44]. On the other hand, the gap values for PXDAN in DMSO with both coordination modes have values closer to the thiol form [43] while the monodentate form in water presents values closer to the toxic agent saxitoxin [35]. If the descriptors for both coordination modes of the nitrate groups are compared in all media their behavior are approximately similar but higher values are observed for the monodentate form than the bidentate ones while Figure S7 shows that there are clear differences in the global electrophilicity indexes between both forms in DMSO and in the nucleophilicity indexes for both forms in gas phase. Note that the global electrophilicity indexes for p-xylylenediaminium in the three media are similar to that value calculated for saxitoxin while these indexes diminishing in the monodentate coordination of PXDAN in the three media, having the lower value in DMSO, as 
observed in Table S10. In addition, these indexes in the bidentate form in gas and, in DMSO present lower values than the monodentate one.

\subsection{Vibrational study}

The experimental PXDAN structure shows monodentate coordination for both nitrate groups but in accordance with studies reported from the literature it is not possible the differentiation between monodentate and bidentate nitrate groups based only on their infrared and Raman spectra $[45,46]$. Later, both coordination modes for the nitrate groups of PXDAN should be considered in this analysis. Hence, the optimized structure in gas phase by using B3LYP/6-311++G** level of theory where their two nitrate groups present monodentate coordination modes has $C_{i}$ symmetry, in accordance with the experimental structure determined by X-ray diffraction. On the other hand, the theoretical proposed structure for PXDAN where both nitrate groups have bidentate coordination modes was optimized by using the $3-21 \mathrm{G}^{*}$ basis set with $C_{2 h}$ symmetry which was confirmed by all positive frequencies. On the contrary, imaginary frequencies were obtained for this same structure by using $6-31 \mathrm{G}^{*}$ basis. For both structures, a total of 90 vibration normal modes are expected for each structure. These modes are classified as $45 \mathrm{Ag}+45 \mathrm{Au}$ for the structure with $C_{i}$ symmetry while for the structure with $C_{2 h}$ symmetry these modes are classified as $61 \mathrm{~A}+29 \mathrm{~B}$. Here, the A modes are symmetrical while the B modes are antisymmetrics and, the symbols $g$ and $u$ are related to the gerade (symmetric) and ungerade (antisymmetric) modes. The symmetry of all vibration normal modes together with the experimental and calculated wavenumbers and the assignments for both coordination modes are presented in Table 7. The assignments for the dimeric monodentate species are also included in Table 5. Here, it is necessary to clarify that the assignments for the monodentate and bidentate forms were performed taking into account the potential energy distribution (PED) contributions $\geq 10 \%$ determined by the SQM procedure [13] while for the dimeric species was used the GaussView program [20]. In Figure 7 is presented the experimental infrared spectrum compared with those predicted in gas phase for both coordination modes including the dimeric species while the predicted Raman spectra for both coordination modes in gas phase can be seen in Figure 8. Figure 6 shows clearly that the monodentate species are not the only present in the solid phase because the strong band predicted for this species at $2477 \mathrm{~cm}^{-1}$ it is not observed in the experimental spectrum and, besides the predicted strong band at $1989 \mathrm{~cm}^{-1}$ for the bidentate species is not observed in the experimental spectrum. Hence, both coordination modes are present 
in the solid phase, as observed in Figure 3 and, as predict the IR spectrum for the dimeric species. Here, the strong band at $1536 \mathrm{~cm}^{-1}$, assigned to the antisymmetric stretching mode of the $\mathrm{NO}_{2}$ group of the monodentate form, the group of bands between 2754 and $2547 \mathrm{~cm}^{-1}$, assigned to the N-H---O stretching modes, and the group of bands between 1779 and $1704 \mathrm{~cm}^{-1}$, assigned to the deformation of $\mathrm{NH}_{3}$ groups, could support clearly the presence of the dimeric species of PXDAN. On the other side, the IR bands at 1986 and $1856 \mathrm{~cm}^{-1}$ could justify the presence of the bidentate species in the solid phase. The assignments for the most important groups of PXDAN are presented below.

\subsubsection{Assignments}

4.7.1.1. $\mathrm{NH}_{3}{ }^{+}$groups. These groups were assigned taking into account $C_{3 v}$ symmetry where the two N5---H6 and N17---H18 bonds coordinated to the nitrate groups have the same characteristics in the monodentate form (see Fig. 1) while in the bidentate one the N5---H6 and N5---H8 bonds together with the N17---H18 and N17---H20 bonds (see Fig. 2) are coordinated to the nitrate groups. Obviously, the nature or characteristics of these bonds are very different and, for these reasons, these modes are observed in different positions. Thus, in the bidentate case, these stretching modes are predicted at higher wavenumbers $\left(3531-3429 \mathrm{~cm}^{-1}\right)$ while in the monodentate case they are predicted at lower wavenumbers (3399-3328 $\mathrm{cm}^{-1}$ ) where the stretching corresponding to the coordinate N---H bonds are predicted between 271 and $119 \mathrm{~cm}^{-1}$, as indicated in Table 4. In m-xylylenediaminium-bis (p-toluenesulfonate) monohydrate [9] these modes are observed in the same region. Here, the symmetry of these modes cannot be assigned because the Raman spectrum for the compound is not presented. In the dimeric species, these stretching modes are predicted between 3550 and $3394 \mathrm{~cm}^{-1}$. Here, it is very important to mention that both coordination modes for the nitrate groups are observed in the dimeric species, as shown in Fig. 3. The deformation modes corresponding to these groups are observed in the regions expected for these groups. Note that the bands located at 1986 and $1856 \mathrm{~cm}^{-1}$ are assigned to the deformation N-H-O modes of the bidentate groups while between 1793 and $1639 \mathrm{~cm}^{-1}$ are predicted the antisymmetric and symmetric deformation modes of these groups for the bidentate coordination modes including the dimeric species. In the monomeric species these modes are predicted between 1597 and $1591 \mathrm{~cm}^{-1}$. The rocking modes of these groups are predicted between 1194 and $1076 \mathrm{~cm}^{-1}$ where in the bidentate case are observed at higher wavenumbers than the monodentate case. Also, in the lower wavenumbers region are predicted these modes for the monodentate coordination. The twisting modes are predicted, as expected, 
at low wavenumbers where for the dimer it is observed between 476 and $419 \mathrm{~cm}^{-1}$ while for the monomeric species these modes are predicted around $30 \mathrm{~cm}^{-1}$.

4.7.1.2. $\mathrm{CH}_{2}$ groups. This species has two $\mathrm{CH}_{2}$ groups, later; four stretching modes are expected for the monodentate and bidentate species, including the dimer and, where two antisymmetrical and symmetrical stretching modes are predicted in the three cases. In the monodentate, these modes are predicted between 2943 and $2899 \mathrm{~cm}^{-1}$ but in the bidentate case are predicted between 3124 and $3076 \mathrm{~cm}^{-1}$. In the dimer, these modes are predicted between 3138 and $3076 \mathrm{~cm}^{-1}$. The deformation modes of these groups are predicted between 1522 and $1516 \mathrm{~cm}^{-1}$ in the dimmer and in the bidentate species while in the monodentate case between 1449 and $1448 \mathrm{~cm}^{-1}$. Hence, they are assigned in these regions. The wagging modes are predicted for the three species between 1437 and 1392 $\mathrm{cm}^{-1}$, having lower wavenumbers the modes corresponding to the monodentate coordination modes. The SQM calculation predicted the rocking modes for the monodentate and bidentate cases between 1360 and $1248 \mathrm{~cm}^{-1}$ while for the dimer these modes are predicted by the calculations between 1366 and $1244 \mathrm{~cm}^{-1}$. The twisting $\mathrm{CH}_{2}$ modes are predicted for the monodentate, bidentate and dimeric species in the same region, it is between 924 and $809 \mathrm{~cm}^{-1}$. Therefore, these modes were assigned as predicted by the SQM calculations and, as observed in Table 4.

4.7.1.3. Nitrate groups. We have considered the two nitrate groups of PXDAN with monodentate coordination modes and, also two with bidentate coordination modes. Hence, in the first case, two $\mathrm{O}=\mathrm{N}=\mathrm{O}$ and one $\mathrm{N}-\mathrm{O}$ stretching modes are expected while in the second one two $\mathrm{O}-\mathrm{N}-\mathrm{O}$ and one $\mathrm{N}=\mathrm{O}$ stretching modes are expected. Usually, the $\mathrm{N}=\mathrm{O}$ stretching modes in some nitrate compounds are observed between 1672 and 1460 $\mathrm{cm}^{-1}$ [1-3] although in $\mathrm{NbO}\left(\mathrm{NO}_{3}\right)_{3}$ these modes are assigned between 1763 and 1753 $\mathrm{cm}^{-1}$ [4]. These modes in the monodentate case are predicted at 1669, 1479, 1277 and $1274 \mathrm{~cm}^{-1}$ while the two N3-O1 and N31-O29 stretching modes are predicted at 928 and $927 \mathrm{~cm}^{-1}$, respectively and, hence, they are associated to the shoulder at $916 \mathrm{~cm}^{-1}$ which is related to the IR band of medium intensity at $896 \mathrm{~cm}^{-1}$. In the bidentate coordination, the $\mathrm{NO}_{2}$ antisymmetric stretching modes are predicted in the $1325-1317 \mathrm{~cm}^{-1}$ region while the corresponding symmetric modes in approximately 1215 and $1210 \mathrm{~cm}^{-1}$, hence, the strong bands observed at $1313 \mathrm{~cm}^{-1}$ is assigned to these stretching modes. In this case, the $\mathrm{N}=\mathrm{O}$ stretching modes are predicted at 1524 and $1523 \mathrm{~cm}^{-1}$ and, for these reasons, they are assigned to the strong IR band observed at $1536 \mathrm{~cm}^{-1}$. In relation to the deformation modes, the two $\mathrm{O}=\mathrm{N}-\mathrm{O}$ deformation modes of both equivalent 
monodentate nitrates are defined as rocking modes which are predicted by calculations at $783 \mathrm{~cm}^{-1}$ while the two $\mathrm{O}=\mathrm{N}=\mathrm{O}$ deformation modes in this case are predicted at 682 and $681 \mathrm{~cm}^{-1}$. Obviously, these modes were assigned to the shoulders and bands located in this region. In the two equivalent bidentate nitrates these deformation modes were assigned to the weak IR band at $731 \mathrm{~cm}^{-1}$ together with the rocking modes because these modes are predicted at $717 \mathrm{~cm}^{-1}$. The wagging modes for both coordination modes are predicted in different regions, thus, in the monodentate case are observed at $652 \mathrm{~cm}^{-1}$ while in the bidentate form are predicted at $821 \mathrm{~cm}^{-1}$. The torsion modes for the monodentate form are predicted at $76 \mathrm{~cm}^{-1}$ while for the bidentate species these modes are defined as $\mathrm{O} 1-\mathrm{H} 6, \mathrm{O} 2-\mathrm{H} 8, \mathrm{O} 29-\mathrm{H} 18$ and $\mathrm{O} 30-\mathrm{H} 20$ torsions and, they are observed between 333 and $32 \mathrm{~cm}^{-1}$, as indicated in Table 5 .

4.7.1.4. Skeletal groups. In the bidentate form, the B3LYP/6-31G* calculations predicted the $\mathrm{C}=\mathrm{C}$ stretching modes corresponding to the benzyl rings of $\mathrm{p}$ xylylenediaminium at $1622 \mathrm{~cm}^{-1}$, as reported in other similar compounds [26-28,44] while in the monodentate form are predicted between 1603 and $1561 \mathrm{~cm}^{-1}$. Consequently, they are assigned in these regions, as predicted by calculations. On the other hand, the SQM calculations predict the C-C stretching modes for both coordination modes between 1243 and $711 \mathrm{~cm}^{-1}$ while the C-N stretching modes for the bidentate species is predicted at $978 \mathrm{~cm}^{-1}$ and for the monodentate form between 975 and $962 \mathrm{~cm}^{-1}$. Hence, they were assigned accordingly. The three expected deformation and torsion rings are predicted normally in the $1000-200 \mathrm{~cm}^{-1}$ region [26-28,44]. Here, the calculations predicted these modes in different regions for the monodentate and bidentate nitrate groups; hence, they obviously are assigned in accordance with the calculations, as shown in Table 5. The other skeletal modes have been assigned according to SQM calculations and they are summarized in Table 5.

\section{Force Field}

In Table 8 it is presented the force constants for p-xylylenediaminium bis(nitrate) calculated considering both monodentate and bidentate coordination modes for the nitrate groups which were compared with those reported for chromyl nitrate [1-3]. The constants were calculated from SQM calculations and by using the Molvib program $[13,14]$. Comparing first the constants for both coordination modes of PXDAN we observed clearly slight changes in the $f(v N=O), f(v N-O)$ and $f\left(v N-H_{3}\right)$ force constants values corresponding to the nitrate and ammonium groups where we observed the higher values for the bidentate coordination while the values corresponding to the 
benzene ring practically do not change, as expected because the ring is not modified. Here, it is very important to note that the value for $f(\delta O=N=O)$ belong to the monodentate coordinaton modes is lower than that observed for the bidentate $f(\delta O-N-O)$ form probably because the corresponding angles present higher value in the bidentate coordination, as can be seen in Table 1. Also, the differences observed could be attributed to the different calculations, that is, different basis sets were used for both coordination modes. When the values for PXDAN are compared with those calculated for chromyl nitrate [1-3] we observed that the values for $f(v N=O)$ and $f(\delta O=N-O)$ are higher in the chromyl compound with both coordination modes while the values for $f(v N-O)$ is low for the monodentate chromyl nitrate. Probably, the different structures and size of the basis sets of the two compared compounds could justify the differences observed.

\section{NMR study}

In Figure 9 it is presented the experimental ${ }^{1} \mathrm{H}$ - and ${ }^{13} \mathrm{C}-\mathrm{NMR}$ spectra of $\mathrm{p}$ xylylenediaminium bis(nitrate) in DMSO solvent while in Tables S11 and S12 are summarized the calculated shifts for both ${ }^{1} \mathrm{H}$ and ${ }^{13} \mathrm{C}$ nuclei compared with those calculated for both coordination modes of PXDAN by using the GIAO method [47]. Here, the RMSD values were used to compare the calculated shifts for both nuclei of PXDAN with the corresponding experimental ones. Besides, our results were also compared with those experimental obtained for $\mathrm{m}$-Xylylenediaminium-bis ( $\mathrm{p}$ toluenesulfonate) monohydrate [9]. These results show a very good correlation for the monodentate form probably because in the bidentate case the basis set used is not the recommended for this study. On the other hand, the calculated shifts for the H6 and H18 atoms were not experimentally observed due to that these atoms are coordinated to the $\mathrm{O}$ atoms of the nitrate groups, as revealed by the AIM analyses for the two coordination modes (Tables S8 and S9). The comparisons with the values obtained for $\mathrm{m}$ xylylenediaminium-bis (p-toluenesulfonate) monohydrate [9] not present good concordance probably because the p-toluenesulfonate groups have influence on the environment of the m-xylylenediaminium group. Here, the RMSD values for the $\mathrm{C}$ atoms show similar and lower correlations for both coordination modes (4.5-4.7 ppm) when they are compared with the experimental ones but Table S12 shows that the higher differences are obtained when are compared with m-xylylenediaminium-bis ( $p$ toluenesulfonate) monohydrate [9]. 


\section{Electronic spectra}

The experimental electronic spectra for PXDAN were recorded in water and in DMSO solvents while for the monodentate coordination modes the UV-Vis spectrum was predicted in water at the B3LYP/6-311++G** level of theory and for the bidentate coordination was predicted in DMSO by using B3LYP/6-311G* level of theory. The experimental and predicted spectra are compared in Figure S8. Experimentally, two bands were observed in water, one strong at $221.4 \mathrm{~nm}$ whiles other less intense at 270.8 $\mathrm{nm}$ and, two shoulders at 296.0 and $309.0 \mathrm{~nm}$. On the other hand, three bands were observed in DMSO solvent located at 227.4, 245.6 and $272.4 \mathrm{~nm}$. The bathochromic shifts to a longer wavelength the first and to lower wavelengths the other two are attributed to the change in solvent polarity. In the UV-Vis spectrum predicted for the monodentate coordination can be seen two bands, one intense at $332.5 \mathrm{~nm}$ and other of lower intensity at $440.0 \mathrm{~nm}$ while for the bidentate coordination in DMSO the two bands are predicted at 300.5 and $416.5 \mathrm{~nm}$. In the UV-Vis spectrum of $\mathrm{m}$ xylylenediaminium-bis (p-toluenesulfonate) monohydrate were observed three bands, one intense at $349 \mathrm{~nm}$ assigned to the $\mathrm{n} \rightarrow \pi^{*}$ transition while other at $224 \mathrm{~nm}$ is attributed to $\pi \rightarrow \pi^{*}$ transition and, the latter band is observed at $403 \mathrm{~nm}$ and is associated to a charge transfer transition. On the other hand, in chromyl nitrate in the gas phase [48] was observed four bands at 214, 282, 316 (shoulder) and $412 \mathrm{~nm}$. The bands at 214 and 316 were assigned to the nitrate groups while the bands at 282 and 412 were attributed to the chromyl groups. In PXDAN, the broad and intense band at 227.4 $\mathrm{nm}$ and the other at $245.6 \mathrm{~nm}$ can be easily assigned to the nitrate groups and to $\pi \rightarrow \pi^{*}$ transitions due to the $\mathrm{C}=\mathrm{C}$ double bonds, as reported for species with those bonds $[49,50]$. Obviously, in the predicted spectra for both coordination modes the intensities and positions of the bands are underestimated, as compared with the experimental ones in both media.

\section{Conclusions}

In this work, the p-xylylenediaminium bis(nitrate) was synthesized and characterized by using FTIR, UV-visible and ${ }^{1} \mathrm{H}$ - and ${ }^{13} \mathrm{C}$-NMR spectroscopies. Two different structures were theoretically proposed for PXDAN considering monodentate and bidentate coordination modes for the nitrate groups which were optimized with $C_{i}$ and $C_{2}$ symmetries by using B3LYP/6-311++G** and B3LYP/6-311G* methods, respectively.

The similarities observed between the predicted parameters for the bidentate 
coordination with the experimental ones suggest the existence of this form in the solid phase. The monodentate species was optimized in water and DMSO while the bidentate ones show imaginary and positive frequencies in water and in dimethylsulfoxide respectively. The monodentate species present higher solvation energies than the bidentate one. The study of the intermolecular interactions by using the Hirshfeld surface analysis shows that the major part of the Hirshfeld surface are occupied by the contacts $\mathrm{O} \ldots \mathrm{H} / \mathrm{H} \ldots \mathrm{O}$ while the AIM study reveals high stability of the bidentate coordination mode. The frontier orbitals shows a low reactivity of the monodentate species than the bidentate one while the vibrational analysis support the presence of both coordination modes in the solid phase, as suggested by the bands belong to the monodentate and bidentate species. The strong band at $1536 \mathrm{~cm}^{-1}$, assigned to the antisymmetric stretching mode of the $\mathrm{NO}_{2}$ group of the monodentate form, the group of bands between 2754 and $2547 \mathrm{~cm}^{-1}$, assigned to the N-H---O stretching modes, and the group of bands between 1779 and $1704 \mathrm{~cm}^{-1}$, assigned to the deformation of $\mathrm{NH}_{3}$ groups, support clearly the presence of the dimeric species of PXDAN while the IR bands at 1986 and $1856 \mathrm{~cm}^{-1}$ could justify the presence of the bidentate species in the solid phase. The Raman spectra for those two coordination modes were also predicted by using the B3LYP/6-311++G** and B3LYP/6-311G* methods, respectively. Reasonable concordances were observed between the experimental FTIR, UV-Visible and ${ }^{1} \mathrm{H}$ and ${ }^{13} \mathrm{C}$-NMR spectra with the corresponding theoretical ones. The complete vibrational assignments for both coordination modes were reported together with the force constants. The values of the computed force constant are in agreement with values reported for molecules containing similar groups.

Acknowledgements. This work was supported with grants from CIUNT (Consejo de Investigaciones, Universidad Nacional de Tucumán) and by the Ministry of Higher Education and Scientific Research of Tunisia. The authors would like to thank Prof. Tom Sundius for his permission to use MOLVIB.

Supporting Information Available: Tables S1-S12 and Figures S1-S8.

\section{References}

[1] S.A. Brandán, Editor "Nitrate: Occurrence, Characteristics and Health Considerations" ISBN: 978-1-62257-352-3, Edited Collection, Nova Science Publishers, Inc. (2012). 
[2] S.A. Brandán, Volume 1: A Structural and Vibrational Study of the Chromyl Chlorosulfate, Fluorosulfate, and Nitrate Compounds, Edited by Ken Derham, Springer Science, Business Media B.V., Van Godewijckstraat 30, 3311 GZ Dordrecht, Netherlands. ISBN: 978-94-007-5762-2 (2012).

[3] S.A. Brandán, Editor of the Book "Descriptors, Structural and spectroscopic Properties of Heterocyclic derivatives of importance for the health and the enviromental", Edited Collection, Nova Science Publishers, Inc. ISBN: 978-1-63482708-9 (2015).

[4] M.V. Castillo, E. Romano, H.E. Lanús, S.B. Díaz, A.Ben Altabef, S.A. Brandán, Theoretical structural and experimental vibrational study of niobyl nitrate, J. Mol. Struct. 994 (2011) 202-208.

[5] K.E. Torfgård, J. Ahlner, Mechanisms of action of nitrates, Cardiovasc Drugs Ther. 8(5) (1994) 701-17.

[6] M.G. Bogaert, Clinical pharmacokinetics of nitrates, Cardiovasc Drugs Ther. 8(5) (1994) 693-699.

[7] H. Cheng, H. Li, (m-Phenylenedimethylene)diammonium dichloride, Acta Cryst. E64 (2008) o2060.

[8] S. Gatfaoui, H. Dhaouadi, T. Roisnel, M. Rzaigui, H. Marouani, mXylylenediaminium dinitrate, Acta Cryst. E70 (2014) o398-o399.

[9] Venkatesan Murugesan, Munusamy Saravanabhavan, Marimuthu Sekar, Synthesis, spectral, structural characterization and biological investigation of $\mathrm{m}$ Xylylenediaminium-bis (p-toluenesulfonate) monohydrate, Journal of Photochemistry and Photobiology B: Biology 148 (2015) 358-365.

[10] A. Guesmi, S. Gatfaoui, T. Roisnel, H. Marouani, m-Xylylenediaminium sulfate: crystal structure and Hirshfeld surface analysis, Acta Cryst. E72 (2016) 776-779.

[11] A.D. Becke, Density-functional exchange-energy approximation with correct asymptotic behavior, Phys. Rev., A38 (1988) 3098-3100.

[12] C. Lee, W. Yang, R.G. Parr. Development of the Colle-Salvetti correlation-energy formula into a functional of the electron density, Phys. Rev. B37 (1988) 785-789.

[13] a) G. Rauhut, P. Pulay, J. Phys. Chem. 99 (1995) 3093-3099. b) Correction: G. Rauhut, P. Pulay, J. Phys. Chem. 99 (1995) 14572.

[14] T. Sundius, Scaling of ab initio force fields by MOLVIB, Vib. Spectrosc. 29 (2002) $89-95$. 
[15] Bruker (2006). APEX2, SAINT and SADABS. Bruker AXS Inc., Madison, Wisconsin, USA.

[16] A. Altomare, M. C. Burla, M. Camalli, G. L. Cascarano, C. Giacovazzo, A. Guagliardi, A. G. G. Moliterni, G. Polidori, R. Spagna, J. Appl. Cryst. 32 (1999) 115.

[17] G. M. Sheldrick, Crystal structure refinement with SHELXL, Acta Cryst. C71 (2015) 3-8.

[18] L. J. Farrugia, WinGX and ORTEP for Windows: an update, J. Appl. Cryst. 45 (2012) 849-854.

[19] A.B. Nielsen, A.J. Holder, Gauss View 3.0, User's Reference, GAUSSIAN Inc., Pittsburgh, PA, 2000-2003.

[20] M.J. Frisch, G. W. Trucks, H.B. Schlegel, G.E. Scuseria, M.A. Robb, J.R. Cheeseman, G. Scalmani, V. Barone, B. Mennucci, G.A. Petersson, H. Nakatsuji, M. Caricato, X. Li, H.P. Hratchian, A.F. Izmaylov, J. Bloino, G. Zheng, J.L. Sonnenberg, M. Hada, M. Ehara, K. Toyota, R. Fukuda, J. Hasegawa, M. Ishida, T. Nakajima, Y. Honda, O. Kitao, H. Nakai, T. Vreven, J.A. Montgomery, Jr., J.E. Peralta, F. Ogliaro, M. Bearpark, J.J. Heyd, E. Brothers, K. N. Kudin, V.N. Staroverov, R. Kobayashi, J. Normand, K. Raghavachari, A. Rendell, J.C. Burant, S.S. Iyengar, J. Tomasi, M. Cossi, N. Rega, J.M. Millam, M. Klene, J.E. Knox, J.B. Cross, V. Bakken, C. Adamo, J. Jaramillo, R. Gomperts, R.E. Stratmann, O. Yazyev, A.J. Austin, R. Cammi, C. Pomelli, J.W. Ochterski, R.L. Martin, K. Morokuma, V.G. Zakrzewski, G.A. Voth, P. Salvador, J.J. Dannenberg, S. Dapprich, A.D. Daniels, O. Farkas, J.B. Foresman, J.V. Ortiz, J. Cioslowski, and D.J. Fox, Gaussian, Inc., Wallingford CT, 2009.

[21] B.H. Besler, K.M. Merz Jr, P.A. Kollman, Atomic charges derived from demiempirical methods, J. Comp. Chem. 11 (1990) 431-439.

[22] S. K. Wolff, D. J. Grimwood, J. J. McKinnon, D. Jayatilaka, M. A. Spackamn, “Crystal Explorer 3.1,” University of Westren Australia, Perth, 2013.

[23] E. D. Glendening, J. K.Badenhoop, A. D. Reed, J. E. Carpenter, F. Weinhold, NBO 3.1; Theoretical Chemistry Institute, University of Wisconsin; Madison, WI, 1996.

Oxford, ISBN: 0198558651, 1990.

[24] F. Biegler-Köning, J. Schönbohm, D. Bayles, AIM2000; A Program to Analyze and Visualize Atoms in Molecules, J. Comput. Chem. 22 (2001) 545.

[25] R. F.W. Bader, Atoms in Molecules. A Quantum Theory, Oxford University Press, Oxford, ISBN: 0198558651, 1990. 
[26] D. Romani, S.A. Brandán, M.J. Márquez, M.B. Márquez, Structural, topological and vibrational properties of an isothiazole derivatives series with antiviral activities, J. Mol. Struct. 1100 (2015) 279-289.

[27] F. Chain, M.A. Iramain, A. Grau, C.A.N. Catalán, S.A. Brandán, Evaluation of the structural, electronic, topological and vibrational properties of $N$-(3,4dimethoxybenzyl)-hexadecanamide isolated from Maca (Lepidium meyenii) using different spectroscopic techniques, J. Mol. Struct. 1119 (2016) 25-38.

[28] N. Issaoui, H. Ghalla, S.A. Brandán, F. Bardak, H.T. Flakus, A. Atac, B. Oujia, Experimental FTIR and FT-Raman and theoretical studies on the molecular structures of monomer and dimer of 3-thiopheneacrylic acid, J. Mol. Structure 1135 (2017) 209221.

[29] S. Miertus, E. Scrocco, J. Tomasi, Electrostatic interaction of a solute with a continuum. Chem. Phys. 55 (1981) 117-129.

[30] J. Tomasi, J. Persico, Molecular Interactions in Solution: An Overview of Methods Based on Continous Distributions of the Solvent, Chem. Rev. 94 (1994) 2027-2094.

[31] A.V. Marenich, C.J. Cramer, D.G. Truhlar, Universal solvation model based on solute electron density and a continuum model of the solvent defined by the bulk dielectric constant and atomic surface tensions, J. Phys. Chem. B113 (2009) 6378-6396. [32] P. Ugliengo, MOLDRAW Program, University of Torino, Dipartimento Chimica IFM, Torino, Italy, 1998.

[33] R. G. Parr, R. G. Pearson, Absolute hardness: companion parameter to absolute electronegativity, J. Am. Chem. Soc. 105 (1983) 7512-7516.

[34] J-L Brédas, Mind the gap!, Materials Horizons 1 (2014) 17-19.

[35] D. Romani, S. Tsuchiya, M. Yotsu-Yamashita, S.A. Brandán, Spectroscopic and structural investigation on intermediates species structurally associated to the tricyclic bisguanidine compound and to the toxic agent, saxitoxin, J. Mol. Struct. 1119 (2016) $25-38$.

[36] S. Gatfaoui, A. Mezni, T. Roisnel, H. Marouani, Synthesis, characterization, Hirshfeld surface analysis and antioxidant activity of a novel organic-inorganic hybrid material 1-methylpiperazine-1,4-diium bis(nitrate), J. Mol. Struct. 1139 (2017) 52-59.

[37] J. H. Nelson, A. N. Sarjeant, A. J. Norquist, Poly[tris( $p$-xylylenediaminium) [tetradeca-l-oxo-hexadecanonamolybdate(VI)] dihydrate], Acta Cryst. E63 (2007) m1442-m1444 
[38] S. K. Seth, G. C. Maity, T. Kar, Structural elucidation, Hirshfeld surface analysis and quantum mechanical study of para-nitro benzylidene methyl arjunolate, J. Mol. Struct. 1000 (2011) 120-126.

[39] E. N. Md Yusof, M. M. Jotani , E. R. T. Tiekink , T. B. S. A. Ravoof , 2-[(1E)( \{[(Benzyl-sulfan-yl)methane-thio-yl $]$ amino $\}$-imino)-meth-yl]-6-meth-oxy-phenol: crystal structure and Hirshfeld surface analysis, Acta Cryst . E72 (2016) 516-521. [40] A.Y. Meyer, The size of molecules, Chem. Soc. Rev. 15 (1986) 449-474.

[41] J. Rudnick, G. Gaspari, The aspherity of random walks, J. Phys. A: Math. Gen. Phys. 19 (1986) L191-L193.

[42] A. Baumgartner, Shapes of flexible vesicles at constant volume, J. Chem. Phys. 99 (1993) 7496-7501.

[43] C. Jelsch, K. Ejsmont, L. Huder, The enrichment ratio of atomic contacts in crystals, an indicator derived from the Hirshfeld surface analysis, IUCrJ, 1, (2014), 119-128.

[43] D. Romani, S. A. Brandán, Structural and spectroscopic studies of two 1,3benzothiazole tautomers with potential antimicrobial activity in different media. Prediction of their reactivities, Comput.Theoret. Chem. (Theochem) 1061 (2015) 89-99. [44] M. B. Márquez, S. A. Brandán, A Structural and Vibrational Investigation on the Antiviral Deoxyribonucleoside Thymidine Agent in Gas and Aqueous Solution PhasesInt. J. Quantum Chem. 114 (2014) 209-221.

[45] (a) C.C. Addison, N. Logan, S.C. Wallwork, C.D. Garner, Q. Rev. Chem. 895 25 (1971) 289; 896. (b) C.C. Addison, N. Logan, Adv. Inorg. Chem. Radiochim. 6 (1964) 71; 897. (c) C.C. Addison, D. Sutton, Prog. Inorg. Chem. 8 (1967) 195. 898

[46] J. Laane, J.R. Ohlsen, Prog. Inorg. Chem. 27 (1980) 465.

[47] R. Ditchfield, Self-consistent perturbation theory of diamagnetism. I. A gageinvariant LCAO (linear combination of atomic orbitals) method for NMR chemical shifts, Mol Phys. 27 (1974) 714-722.

[48] E.L.Varetti, S.A. Brandán, A.Ben Altabef, The electronic and FTIR and Raman spectra of chromyl nitrate, $\mathrm{CrO}_{2}\left(\mathrm{NO}_{3}\right)_{2}$, Vibrational Spectr., 5 (1993) 219-225.

[49] T.J. Bruno, P.D.N. Svoronos, CRC Handbook of Basic Tables for Chemical Analysis, Second Edition, CRC Press, Taylor \& Francis Goup, Boca Raton, 2011.

[50] R. A. Friedel, M. Orchin, Ultraviolet spectra of aromatic compounds, Wiley \& Sons, New York and London, 1951. 


\section{Caption Figures}

Figure 1. ORTEP drawing of PXDAN with the atom-labeling scheme. Displacement ellipsoids are drawn at the $30 \%$ probability level (i: -x, -y, -z). H atoms are represented

as small spheres of arbitrary radii (a). Projection along the $\vec{a}$ axis of atomic arrangement of PXDAN (b). Assembly of organic cations by $\mathrm{C}-\mathrm{H}$.... $\pi$ interactions in the PXDAN structure (c).

Figure 2. The molecular structure of p-xylylenediaminium bis(nitrate) (PXDAN) and the atoms numbering considering the nitrate groups as monodentate ligands.

Figure 3. The molecular structure of p-xylylenediaminium bis(nitrate) (PXDAN) and the atoms numbering considering the nitrate groups as bidentate ligands.

Figure 4. The molecular dimeric structure of p-xylylenediaminium bis(nitrate) (PXDAN) and the atoms numbering. The blue circles indicates monodentate nitrate while the red one bidentate nitrate.

Figure 5. Hirshfeld surfaces mapped with $d_{\text {norm }}($ a) (dotted lines "red" represent hydrogen bonds), shape index (b) and curvedness (c) for the PXDAN.

Figure 6. Fingerprint plots of the full and the import intercontacts and percentage of various intermolecular contacts contributed to the Hirshfeld surface in the PXDAN compound.

Figure 7. Comparisons between the experimental available FTIR spectrum of PXDAN with the corresponding predicted for the monodentate, bidentate and dimeric species of PXDAN in the gas phase by using B3LYP level of theory.

Figure 8. Comparisons between the predicted Raman spectra of PXDAN considering monodentate and bidentate coordination modes for the nitrate groups in the gas phase by using B3LYP level of theory.

Figure 9. Experimental ${ }^{1} \mathrm{H}$ - and ${ }^{13} \mathrm{C}-\mathrm{NMR}$ spectra of p-xylylenediaminium bis(nitrate) in DMSO solvent. 
Table 1. Crystal data and experimental parameters used for the intensity data collection strategy and final results of the structure determination.

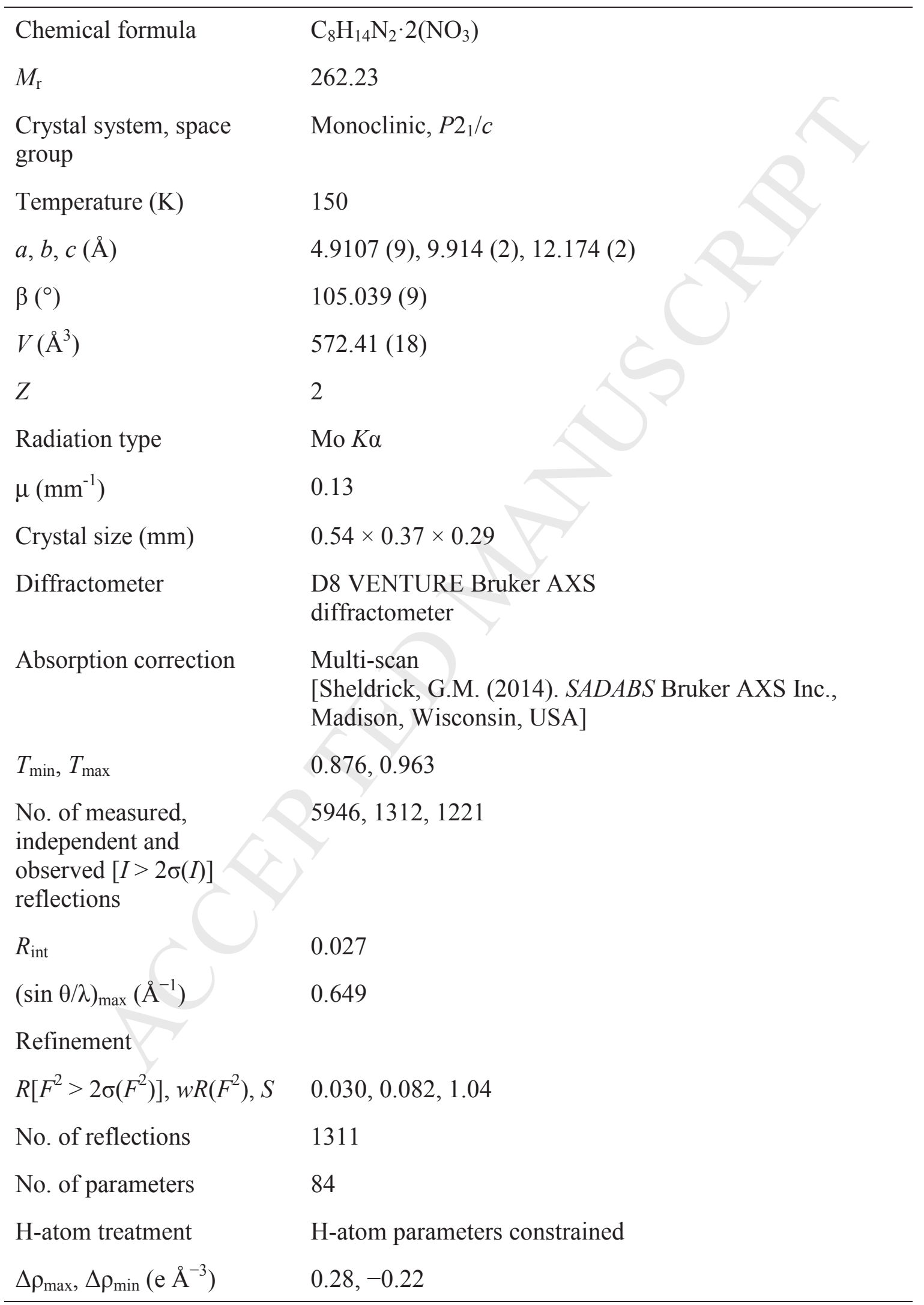


Table 2. Hydrogen-bonds geometry $\left(\AA,^{\circ}\right)$ in PXDAN.

\begin{tabular}{lllll}
\hline$D-\mathrm{H} \cdots A$ & $D-\mathrm{H}$ & $\mathrm{H} \cdots A$ & $D \cdots A$ & $D-\mathrm{H} \cdots A$ \\
\hline $\mathrm{N} 2-\mathrm{H} 2 \mathrm{~A} \cdots \mathrm{O} 2$ & 0.89 & 2.04 & $2.9149(12)$ & 168.0 \\
$\mathrm{~N} 2-\mathrm{H} 2 \mathrm{~A} \cdots \mathrm{O} 1$ & 0.89 & 2.57 & $3.0522(12)$ & 114.8 \\
$\mathrm{~N} 2-\mathrm{H} 2 \mathrm{~B} \cdots \mathrm{O} 1^{\mathrm{i}}$ & 0.89 & 1.97 & $2.8353(12)$ & 164.7 \\
$\mathrm{~N} 2-\mathrm{H} 2 \mathrm{C} \cdots \mathrm{O} 2^{\mathrm{ii}}$ & 0.89 & 2.05 & $2.9041(11)$ & 161.8 \\
$\mathrm{C} 4-\mathrm{H} 4 \cdots \mathrm{O} 1^{\mathrm{iii}}$ & 0.93 & 2.55 & $3.4445(13)$ & 161.7 \\
$\mathrm{C} 3-\mathrm{H} 3 \cdots \mathrm{Cg}^{\mathrm{iii}}$ & 0.93 & 3.48 & 3.951 & 114.3 \\
\hline
\end{tabular}

Symmetry codes: (i) $-x, y-1 / 2,-z+1 / 2$; (ii) $x-1, y, z$; (iii) $-x, y+1 / 2,-z+1 / 2$. $\mathrm{Cg}$ is the centroid of the benzene ring. 
Table 3. Comparison of calculated geometrical parameters of p-xylylenediaminium bis(nitrate) with the corresponding experimental ones

\begin{tabular}{|c|c|c|c|c|c|}
\hline \multicolumn{5}{|c|}{ B3LYP method } & \multirow{3}{*}{ Experimental } \\
\hline \multirow{2}{*}{ Parameters } & \multicolumn{2}{|c|}{ Monodentate } & \multicolumn{2}{|c|}{ Bidentate } & \\
\hline & $6-311++\mathrm{G}^{* *}$ & $6-311+\mathrm{G}^{*}$ & $6-311 \mathrm{G}^{*}$ & $6-311++\mathrm{G}^{* *}$ & \\
\hline & \multicolumn{4}{|c|}{ Bond lengths $(\AA)$} & 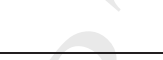 \\
\hline O1-N3 & 1.370 & 1.310 & 1.257 & 1.223 & $1.2580(11)$ \\
\hline $\mathrm{O} 2-\mathrm{N} 3$ & 1.221 & 1.252 & 1.306 & 1.370 & $1.2670(11)$ \\
\hline O4-N3 & 1.204 & 1.218 & 1.218 & 1.204 & $1.2341(11)$ \\
\hline N5-H6 & 1.614 & 1.131 & 1.024 & 1.018 & 0.890 \\
\hline $\mathrm{N} 5-\mathrm{H} 7$ & 1.017 & 1.019 & 1.018 & 1.018 & 0.890 \\
\hline N5-H8 & 1.018 & 1.022 & 1.125 & 1.626 & 0.890 \\
\hline N5-C11 & 1.487 & 1.501 & 1.501 & 1.487 & $1.495(13)$ \\
\hline C11-C16 & 1.511 & 1.509 & 1.508 & 1.511 & $1.509(14)$ \\
\hline O29-N31 & 1.370 & 1.310 & 1.306 & 1.370 & $1.2580(11)$ \\
\hline O30-N31 & 1.221 & 1.252 & 1.257 & 1.223 & $1.2670(11)$ \\
\hline O32-N31 & 1.204 & 1.218 & 1.218 & 1.204 & $1.2341(11)$ \\
\hline N17-H18 & 1.614 & 1.131 & 1.125 & 1.626 & 0.890 \\
\hline N17-H19 & 1.017 & 1.019 & 1.018 & 1.018 & 0.890 \\
\hline N17-H20 & 1.018 & 1.022 & 1.024 & 1.018 & 0.890 \\
\hline N17-C23 & 1.487 & 1.501 & 1.501 & 1.487 & $1.496(13)$ \\
\hline C23-C28 & 1.511 & 1.509 & 1.508 & 1.511 & $1.510(13)$ \\
\hline C9-C14 & 1.392 & 1.391 & 1.389 & 1.390 & $1.390(14)$ \\
\hline C9-C16 & 1.398 & 1.398 & 1.398 & 1.400 & $1.393(14)$ \\
\hline C14-C28 & 1.398 & 1.398 & 1.398 & 1.400 & $1.397(14)$ \\
\hline $\mathrm{C} 16-\mathrm{C} 26$ & 1.398 & 1.398 & 1.396 & 1.396 & $1.393(14)$ \\
\hline $\mathrm{C} 26-\mathrm{C} 21$ & 1.392 & 1.391 & 1.392 & 1.394 & $1.390(14)$ \\
\hline $\mathrm{C} 21-\mathrm{C} 28$ & 1.398 & 1.398 & 1.396 & 1.396 & $1.397(14)$ \\
\hline O1-H6 & 1.039 & 1.436 & 2.193 & 2.653 & 1.967 \\
\hline $\mathrm{O} 29-\mathrm{H} 18$ & 1.039 & 1.436 & 1.453 & 1.037 & 2.044 \\
\hline RMSD $^{\mathbf{b}}$ & 0.884 & 0.928 & 0.989 & 1.015 & \\
\hline \multicolumn{6}{|c|}{$\sqrt{2}+2$} \\
\hline O1-N3-O2 & 117.0 & 117.452 & 117.690 & 117.153 & $118.23(8)$ \\
\hline O1-N3-O4 & 115.3 & 118.950 & 123.116 & 127.505 & $121.11(8)$ \\
\hline $\mathrm{O} 2-\mathrm{N} 3-\mathrm{O} 4$ & 117.6 & 123.596 & 119.194 & 115.341 & $120.66(8)$ \\
\hline N5-H6-O1 & 176.5 & 173.033 & 115.497 & 104.823 & 109.470 \\
\hline C11-N5-H6 & 117.6 & 112.887 & 112.692 & 110.493 & 109.460 \\
\hline C16-C11-N5 & 111.2 & 111.276 & 110.966 & 111.048 & 111.894(8) \\
\hline O29-N31-O30 & 117.0 & 117.452 & 117.690 & 117.153 & $118.223(8)$ \\
\hline O29-N31-O32 & 115.3 & 118.950 & 119.194 & 115.341 & 121.111(8) \\
\hline O32-N31-O30 & 127.6 & 123.596 & 123.116 & 127.505 & $120.665(8)$ \\
\hline
\end{tabular}




\section{ACCEPTED MANUSCRIPT}

\begin{tabular}{lccccc} 
N17-H18-O29 & 176.5 & 173.033 & 168.706 & 179.905 & 167.984 \\
C23-N17-H18 & 117.6 & 112.887 & 113.552 & 118.970 & 109.460 \\
C28-C23-N17 & 111.2 & 111.276 & 110.966 & 111.048 & $111.890(8)$ \\
C14-C28-C21 & 118.5 & 119.148 & 119.185 & 118.588 & $118.990(9)$ \\
C9-C16-C26 & 118.5 & 119.148 & 119.185 & 118.588 & $118.990(9)$ \\
\hline RMSD $^{\mathbf{b}}$ & $\mathbf{1 8 . 6}$ & $\mathbf{1 7 . 2}$ & $\mathbf{2 . 4}$ & $\mathbf{5 . 4}$ & \\
\hline & & Dihedral angles $\left(^{\circ}\right)$ & & \\
\hline O4-N3-O1-H6 & -177.4 & -173.922 & -171.352 & -173.369 & \\
N3-O1-H6-N5 & 175.5 & 29.088 & -5.227 & -13.403 & \\
O1-H6-N5-C11 & -35.2 & 95.204 & 119.817 & 134.366 & \\
C16-C11-N5-H6 & -62.8 & -65.832 & -53.763 & -58.666 & \\
O32-N31-O29-H18 & 177.4 & 173.922 & 173.187 & 177.154 & \\
N31-O29-H18-N17 & -175.5 & -29.088 & -9.495 & 177.154 & \\
O29-H18-N17-C23 & 35.2 & -95.204 & -107.166 & -31.870 & \\
C28-C23-N17-H18 & 62.8 & 65.832 & 58.397 & 56.820 & \\
\hline
\end{tabular}


Table 4. Comparison of calculated geometrical parameters of p-xylylenediaminium bis(nitrate) in aqueous solution and dimethylsulfoxide solvent with the corresponding experimental ones

\begin{tabular}{|c|c|c|c|c|c|}
\hline \multicolumn{5}{|c|}{ B3LYP method } & \multirow{3}{*}{ Experimental } \\
\hline \multirow{2}{*}{ Parameters } & \multicolumn{2}{|c|}{ Monodentate/6-311++G** } & \multicolumn{2}{|c|}{ Bidentate/6-311G* } & \\
\hline & Water & DMSO & Water & DMSO & \\
\hline & \multicolumn{4}{|c|}{ Bond lengths $(\AA)$} & - \\
\hline O1-N3 & 1.267 & 1.279 & 1.251 & 1.251 & $1.258(11)$ \\
\hline $\mathrm{O} 2-\mathrm{N} 3$ & 1.252 & 1.253 & 1.272 & 1.284 & $1.267(11)$ \\
\hline O4-N3 & 1.251 & 1.243 & 1.246 & 1.239 & $1.234(11)$ \\
\hline N5-H6 & 1.043 & 1.057 & 1.021 & 1.021 & 0.890 \\
\hline N5-H7 & 1.023 & 1.023 & 1.021 & 1.021 & 0.890 \\
\hline N5-H8 & 1.023 & 1.023 & 1.045 & 1.060 & 0.890 \\
\hline N5-C11 & 1.507 & 1.506 & 1.507 & 1.503 & $1.495(13)$ \\
\hline $\mathrm{C} 11-\mathrm{C} 16$ & 1.506 & 1.508 & 1.505 & 1.507 & $1.509(14)$ \\
\hline O29-N31 & 1.267 & 1.279 & 1.272 & 1.284 & $1.258(11)$ \\
\hline O30-N31 & 1.253 & 1.253 & 1.251 & 1.251 & $1.267(11)$ \\
\hline O32-N31 & 1.251 & 1.243 & 1.246 & 1.239 & $1.234(11)$ \\
\hline N17-H18 & 1.043 & 1.057 & 1.045 & 1.060 & 0.890 \\
\hline N17-H19 & 1.023 & 1.023 & 1.021 & 1.021 & 0.890 \\
\hline N17-H20 & 1.023 & 1.023 & 1.021 & 1.021 & 0.890 \\
\hline $\mathrm{N} 17-\mathrm{C} 23$ & 1.508 & 1.506 & 1.507 & 1.503 & $1.496(13)$ \\
\hline $\mathrm{C} 23-\mathrm{C} 28$ & 1.506 & 1.508 & 1.505 & 1.507 & $1.510(14)$ \\
\hline C9-C14 & 1.392 & 1.392 & 1.391 & 1.392 & $1.390(14)$ \\
\hline C9-C16 & 1.399 & 1.399 & 1.399 & 1.399 & $1.393(14)$ \\
\hline C14-C28 & 1.399 & 1.399 & 1.399 & 1.399 & 1.39714) \\
\hline $\mathrm{C} 16-\mathrm{C} 26$ & 1.398 & 1.399 & 1.397 & 1.398 & $1.393(14)$ \\
\hline $\mathrm{C} 26-\mathrm{C} 21$ & 1.085 & 1.392 & 1.393 & 1.393 & $1.390(14)$ \\
\hline $\mathrm{C} 21-\mathrm{C} 28$ & 1.398 & 1.399 & 1.397 & 1.398 & $1.397(14)$ \\
\hline O1-H6 & 1.806 & 1.694 & 3.214 & 2.854 & 1.967 \\
\hline O29-H18 & 1.806 & 1.695 & 1.777 & 1.666 & 2.044 \\
\hline RMSD $^{\mathbf{b}}$ & 0.966 & 0.965 & 1.120 & 1.071 & \\
\hline \multicolumn{6}{|c|}{ 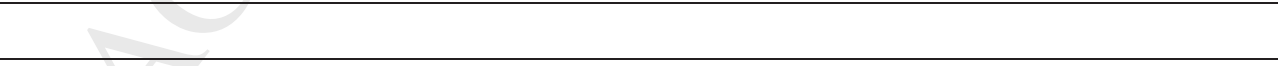 } \\
\hline $\mathrm{O} 1-\mathrm{N} 3-\mathrm{O} 2$ & 119.685 & 118.853 & 119.571 & 118.795 & $118.223(8)$ \\
\hline O1-N3-O4 & 119.522 & 119.480 & 121.083 & 121.943 & $121.111(8)$ \\
\hline O2-N3-O4 & 120.793 & 121.667 & 119.346 & 119.262 & $120.665(8)$ \\
\hline N5-H6-O1 & 175.498 & 177.062 & 129.555 & 94.330 & 109.470 \\
\hline C11-N5-H6 & 111.200 & 112.646 & 110.992 & 111.293 & 109.460 \\
\hline C16-C11-N5 & 111.279 & 111.496 & 111.452 & 111.338 & 111.894(8) \\
\hline O29-N31-O30 & 119.695 & 118.854 & 119.572 & 118.795 & $118.223(8)$ \\
\hline O29-N31-O32 & 119.531 & 119.481 & 119.345 & 119.262 & $121.111(8)$ \\
\hline O32-N31-O30 & 120.775 & 121.665 & 121.083 & 121.943 & $120.665(8)$ \\
\hline
\end{tabular}




\section{ACCEPTED MANUSCRIPT}

\begin{tabular}{lccccc} 
N17-H18-O29 & 175.277 & 177.041 & 173.301 & 176.583 & 167.984 \\
C23-N17-H18 & 111.366 & 112.646 & 111.126 & 111.943 & 109.460 \\
C28-C23-N17 & 111.458 & 111.497 & 111.460 & 111.338 & $111.890(8)$ \\
C14-C28-C21 & 119.151 & 118.962 & 119.086 & 118.994 & $118.990(9)$ \\
C9-C16-C26 & 119.149 & 118.962 & 119.085 & 118.994 & $118.990(9)$ \\
\hline RMSD $^{\mathbf{b}}$ & $\mathbf{1 7 . 8}$ & $\mathbf{1 8 . 3}$ & $\mathbf{5 . 6}$ & $\mathbf{4 . 8}$ & \\
\hline & & Dihedral angles $\left(^{\circ}\right)$ & & \\
\hline O4-N3-O1-H6 & -178.967 & -178.595 & -174.042 & -176.153 & \\
N3-O1-H6-N5 & 167.579 & -107.077 & 27.532 & -6.971 & \\
O1-H6-N5-C11 & -67.194 & -105.403 & 106.992 & 126.589 & \\
C16-C11-N5-H6 & -61.384 & -64.421 & -55.356 & -56.171 & \\
O32-N31-O29-H18 & 174.136 & 178.600 & -173.949 & 178.352 & \\
N31-O29-H18-N17 & -176.800 & 106.914 & -175.675 & -170.131 & \\
O29-H18-N17-C23 & 47.687 & 105.610 & 74.806 & 43.134 & \\
C28-C23-N17-H18 & 63.530 & 64.439 & 65.286 & 64.411 & \\
\hline
\end{tabular}


Table 5. Quantitative measurements of XDAN.

\begin{tabular}{cccc}
\hline Volume $\left(\AA^{3}\right)$ & Surface area $\left(\AA^{2}\right)$ & Globularity & Asphericity \\
\hline 231.50 & 233.43 & 0.781 & 0.098 \\
\hline
\end{tabular}


Table 6. Enrichment ratio of different inter-contact and percentage of each atom on the surface Hirshfeld in PXDAN.

\begin{tabular}{ccccc}
\hline Enrichment & $\mathrm{H}$ & $\mathrm{N}$ & $\mathrm{O}$ & $\mathrm{C}$ \\
\hline $\mathrm{H}$ & 0.65 & 1.40 & 1.54 & 1.43 \\
$\mathrm{~N}$ & & & & 3 \\
$\mathrm{O}$ & & & 0.2 & 0.36 \\
$\mathrm{C}$ & & & & 0.69 \\
\hline \% Surface & 59.5 & 1.85 & 33.1 & 5.4 \\
\hline
\end{tabular}


Table 7. Observed and calculated wavenumbers $\left(\mathrm{cm}^{-1}\right)$ and assignments for $\mathrm{p}$ xylylenediaminium bis(nitrate) considering monodentate and bidentate coordination modes for the nitrate groups

\begin{tabular}{|c|c|c|c|c|c|c|c|c|}
\hline \multirow{3}{*}{$\begin{array}{l}\text { Exp }^{\mathrm{a}} \\
\text { FTIR } \\
\end{array}$} & \multicolumn{3}{|c|}{ B3LYP/6-311++G** Method $^{\text {a }}$} & \multicolumn{3}{|c|}{ B3LYP/6-311G* Method ${ }^{\text {a }}$} & \multicolumn{2}{|c|}{ B3LYP/6-311+G* Method ${ }^{\text {a }}$} \\
\hline & \multicolumn{3}{|c|}{ Monodentate } & \multicolumn{3}{|c|}{ Bidentate } & \multicolumn{2}{|c|}{ Dimer Monodentate } \\
\hline & $\mathrm{SQM}^{\mathrm{b}}$ & Sym & Assignments $^{\mathrm{b}}$ & $\mathrm{SQM}^{\mathrm{b}}$ & Sym & Assignments $^{\mathrm{b}}$ & Calc & Assignments \\
\hline $3550 \mathrm{vw}$ & & & & 3531 & A & $\mathrm{v}_{\mathrm{a}} \mathrm{NH}_{3}(\mathrm{~N} 5)$ & 3541 & $v_{\mathrm{a}} \mathrm{NH}_{3}$ \\
\hline $3474 \mathrm{vw}$ & & & & 3530 & B & $v_{\mathrm{a}} \mathrm{NH}_{3}(\mathrm{~N} 17)$ & 3473 & $v_{\mathrm{s}} \mathrm{NH}_{3}$ \\
\hline \multirow[t]{2}{*}{$3439 \mathrm{vw}$} & & & & 3429 & A & $v_{\mathrm{s}} \mathrm{NH}_{3}(\mathrm{~N} 17), v_{\mathrm{a}} \mathrm{NH}_{3}(\mathrm{~N} 17)$ & 3455 & $v_{\mathrm{s}} \mathrm{NH}_{3}$ \\
\hline & & & & 3429 & B & $\mathrm{V}_{\mathrm{S}} \mathrm{NH}_{3}(\mathrm{~N} 5)$ & & \\
\hline $3395 \mathrm{vw}$ & & & & & & & 3394 & $v_{s} \mathrm{NH}_{3}$ \\
\hline $3345 \mathrm{vw}$ & & & & 3199 & A & vC9-H10 & 3204 & $\mathrm{vC}-\mathrm{H}$ \\
\hline \multicolumn{9}{|l|}{$3303 \mathrm{vw}$} \\
\hline & & & & 3185 & B & vC14-H15 & 3188 & $v \mathrm{C}-\mathrm{H}$ \\
\hline & & & & 3174 & A & $v \mathrm{C} 26-\mathrm{H} 27$ & 3174 & vN-H---O \\
\hline $3156 \mathrm{sh}$ & 3399 & $\mathrm{~A}_{\mathrm{G}}$ & $\mathrm{v}_{\mathrm{a}} \mathrm{NH}_{3}(\mathrm{~N} 5)$ & 3157 & B & vC21-H22 & 3162 & $v \mathrm{C}-\mathrm{H}$ \\
\hline $3136 \mathrm{sh}$ & 3399 & $\mathrm{~A}_{U}$ & $v_{\mathrm{a}} \mathrm{NH}_{3}(\mathrm{~N} 17)$ & 3124 & B & $v_{\mathrm{a}} \mathrm{CH}_{2}(\mathrm{C} 11)$ & 3144 & $v_{\mathrm{a}} \mathrm{CH}_{2}$ \\
\hline \multirow[t]{2}{*}{$3120 \mathrm{sh}$} & 3329 & $\mathrm{~A}_{\mathrm{G}}$ & $v_{\mathrm{s}} \mathrm{NH}_{3}(\mathrm{~N} 17)$ & 3124 & A & $v_{\mathrm{a}} \mathrm{CH}_{2}(\mathrm{C} 23)$ & 3138 & $v_{\mathrm{a}} \mathrm{CH}_{2}$ \\
\hline & & & & & & & 3131 & $\mathrm{v}_{\mathrm{a}} \mathrm{CH}_{2}$ \\
\hline \multirow[t]{4}{*}{$3092 \mathrm{~s}$} & 3328 & $\mathrm{~A}_{U}$ & $v_{\mathrm{s}} \mathrm{NH}_{3}(\mathrm{~N} 17)$ & & & & 3090 & $v_{\mathrm{s}} \mathrm{CH}_{2}$ \\
\hline & & & & 3076 & A & $v_{s} \mathrm{CH}_{2}(\mathrm{C} 23)$ & 3087 & $\nu_{\mathrm{s}} \mathrm{CH}_{2}$ \\
\hline & & & & 3076 & B & $v_{s} \mathrm{CH}_{2}(\mathrm{C} 11)$ & 3070 & $v_{\mathrm{s}} \mathrm{CH}_{2}$ \\
\hline & 3050 & $\mathrm{~A}_{\mathrm{G}}$ & vC26-H27 & & & & & \\
\hline 3040sh & 3048 & $\mathrm{~A}_{U}$ & vC14-H15 & & & & & \\
\hline $3028 \mathrm{sh}$ & 3029 & $\mathrm{~A}_{\mathrm{G}}$ & vC9-H10 & & & & & \\
\hline \multirow[t]{2}{*}{$2977 \mathrm{~s}$} & 3029 & $\mathrm{~A}_{U}$ & vC21-H22 & & & & & \\
\hline & 2943 & $\mathrm{~A}_{\mathrm{G}}$ & $v_{\mathrm{a}} \mathrm{CH}_{2}(\mathrm{C} 11)$ & & & & & \\
\hline \multirow[t]{3}{*}{ 2913sh } & 2943 & $\mathrm{~A}_{\mathrm{U}}$ & $v_{\mathrm{a}} \mathrm{CH}_{2}(\mathrm{C} 23)$ & & & & & \\
\hline & 2899 & $\mathrm{~A}_{\mathrm{G}}$ & $v_{\mathrm{s}} \mathrm{CH}_{2}(\mathrm{C} 11)$ & & & & & \\
\hline & 2899 & $\mathrm{~A}_{\mathrm{U}}$ & $\mathrm{v}_{\mathrm{s}} \mathrm{CH}_{2}(\mathrm{C} 23)$ & & & & & \\
\hline $2754 w$ & & & & & & & 2811 & vN-H---O \\
\hline $2654 \mathrm{~m}$ & 2379 & $\mathrm{~A}_{\mathrm{G}}$ & vO1-H6 & & & & & \\
\hline $2642 \mathrm{sh}$ & 2377 & $\mathrm{~A}_{U}$ & vO29-H18 & & & & 2640 & vN-H---O \\
\hline $2547 \mathrm{vw}$ & & & & & & & 2466 & $v \mathrm{~N}-\mathrm{H}---\mathrm{O}$ \\
\hline $1986 \mathrm{w}$ & & & & 1997 & A & $\delta \mathrm{N} 5 \mathrm{H} 6 \mathrm{O} 1$ & & \\
\hline $1856 \mathrm{w}$ & & & & 1994 & B & $\begin{array}{l}\delta \mathrm{N} 17 \mathrm{H} 18 \mathrm{O} 29, \\
\delta \mathrm{N} 5 \mathrm{H} 6 \mathrm{O} 1\end{array}$ & & \\
\hline $1779 \mathrm{vw}$ & & & & & & & 1793 & $\mathrm{SaNH}_{3}$ \\
\hline $1758 \mathrm{vw}$ & & & & & & & 1747 & $\mathrm{\delta aNH}_{3}$ \\
\hline $1704 \mathrm{vw}$ & & & & & & & 1743 & $\mathrm{SaNH}_{3}$ \\
\hline $1691 \mathrm{vw}$ & & & & 1692 & A & $\begin{array}{l}\delta \mathrm{aNH}_{3}(\mathrm{~N} 5) \\
\delta \mathrm{N} 17 \mathrm{H} 18 \mathrm{O} 29\end{array}$ & 1721 & $\mathrm{SaNH}_{3}$ \\
\hline $1685 w$ & & $\delta \mathrm{sNH}_{3}$ & & 1692 & B & $\delta \mathrm{aNH}_{3}(\mathrm{~N} 5)$ & 1675 & $\delta \mathrm{sNH}_{3}$ \\
\hline $1685 w$ & 1669 & $A_{U}$ & $v_{\mathrm{a}} \mathrm{NO}_{2}(\mathrm{~N} 3), \delta \mathrm{H} 6 \mathrm{O} 1 \mathrm{~N} 3$ & 1663 & A & $\delta \mathrm{aNH}_{3}(\mathrm{~N} 17)$ & 1667 & $\mathrm{SsNH}_{3}$ \\
\hline \multirow[t]{2}{*}{$1685 \mathrm{w}$} & 1669 & $\mathrm{~A}_{\mathrm{G}}$ & $v_{\mathrm{a}} \mathrm{NO}_{2}(\mathrm{~N} 31), \delta \mathrm{H} 18 \mathrm{O} 29 \mathrm{~N} 31$ & 1661 & B & $\delta \mathrm{N} 17 \mathrm{H} 18 \mathrm{O} 29$ & & \\
\hline & & & & 1661 & A & $\delta \mathrm{aNH}_{3}(\mathrm{~N} 5)$ & & \\
\hline $1644 \mathrm{sh}$ & & & & 1640 & A & $\delta \mathrm{sNH}_{3}(\mathrm{~N} 17)$ & 1652 & $\delta \mathrm{sNH}_{3}$ \\
\hline 1639sh & & & & 1639 & B & $\delta \mathrm{sNH}_{3}(\mathrm{~N} 5)$ & 1639 & $\mathrm{SsNH}_{3}$ \\
\hline $1627 \mathrm{~m}$ & & & & 1622 & B & $\begin{array}{l}v \mathrm{C} 16-\mathrm{C} 26, v \mathrm{C} 21-\mathrm{C} 28 \\
v \mathrm{C} 14-\mathrm{C} 28, v \mathrm{C} 9-\mathrm{C} 16\end{array}$ & 1623 & $v \mathrm{C}-\mathrm{C}$ \\
\hline $1617 \mathrm{sh}$ & & & & & & & 1617 & $\delta \mathrm{sNH}_{3}$ \\
\hline $1609 \mathrm{sh}$ & 1603 & $\mathrm{~A}_{\mathrm{G}}$ & vC9-C14 & & & & & \\
\hline $1597 \mathrm{sh}$ & 1577 & $\mathrm{~A}_{U}$ & $\delta \mathrm{aNH}_{3}(\mathrm{~N} 5), \delta \mathrm{sCH}_{3}(\mathrm{~N} 17)$ & & & & & \\
\hline $1591 \mathrm{sh}$ & 1575 & $\mathrm{~A}_{\mathrm{G}}$ & $\delta \mathrm{aNH}_{3}(\mathrm{~N} 17), \delta \mathrm{sNH}_{3}(\mathrm{~N} 5)$ & & & & & \\
\hline $1552 \mathrm{sh}$ & 1561 & $\mathrm{~A}_{\mathrm{G}}$ & vC16-C26,vC14-C28 & 1556 & B & $\beta C 9-\mathrm{H} 10$ & 1560 & $\beta \mathrm{C}-\mathrm{H}$ \\
\hline
\end{tabular}


vC9-C16

\begin{tabular}{|c|c|c|c|c|c|c|c|c|}
\hline $1536 \mathrm{~s}$ & & & & 1524 & A & $v \mathrm{~N} 3=\mathrm{O} 1$ & 1535 & $\mathrm{~V}_{\mathrm{a}} \mathrm{NO}_{2}$ \\
\hline $1521 \mathrm{sh}$ & & & & 1523 & B & $v \mathrm{~N} 31=\mathrm{O} 29$ & 1522 & $\delta \mathrm{CH}_{2}$ \\
\hline 1519sh & & & & 1515 & A & $\delta \mathrm{CH}_{2}(\mathrm{C} 11), \delta \mathrm{CH}_{2}(\mathrm{C} 23)$ & 1517 & $\delta \mathrm{CH}_{2}$ \\
\hline $1519 \mathrm{sh}$ & & & & 1514 & B & $\delta \mathrm{N} 17 \mathrm{H} 18 \mathrm{O} 29, \delta \mathrm{N} 5 \mathrm{H} 6 \mathrm{O} 1$ & 1516 & $\delta \mathrm{CH}_{2}$ \\
\hline $1508 \mathrm{sh}$ & 1501 & $\mathrm{~A}_{\mathrm{U}}$ & $\beta \mathrm{C} 26-\mathrm{H} 27, \beta \mathrm{C} 14-\mathrm{H} 15$ & & & & 1503 & $v \mathrm{~N}=\mathrm{Ov}_{\mathrm{a}} \mathrm{NO}_{2}$ \\
\hline $1473 \mathrm{~m}$ & 1480 & $\mathrm{~A}_{\mathrm{G}}$ & $\delta \mathrm{N} 17 \mathrm{H} 18 \mathrm{O} 29$ & & & & 1489 & $v \mathrm{~N}=\mathrm{Ov}_{\mathrm{a}} \mathrm{NO}_{2}$ \\
\hline $1473 m$ & 1479 & $\mathrm{~A}_{U}$ & $v_{\mathrm{a}} \mathrm{NO}_{2}(\mathrm{~N} 3), \mathrm{v}_{\mathrm{a}} \mathrm{NO}_{2}(\mathrm{~N} 31)$ & 1463 & A & $v \mathrm{C} 21-\mathrm{C} 26$ & 1467 & $v_{\mathrm{a}} \mathrm{NO}_{2} \beta \mathrm{C}-\mathrm{H}$ \\
\hline $1465 \mathrm{sh}$ & 1449 & $\mathrm{~A}_{\mathrm{G}}$ & $\delta \mathrm{CH}_{2}(\mathrm{C} 23)$ & & & & 1462 & $v_{\mathrm{a}} \mathrm{NO}_{2} \beta \mathrm{C}-\mathrm{H}$ \\
\hline 1440sh & 1448 & $\mathrm{~A}_{U}$ & $\delta \mathrm{CH}_{2}(\mathrm{C} 11)$ & & & & & \\
\hline $1433 \mathrm{sh}$ & & & & & & & 1437 & wagCH${ }_{2}$ \\
\hline $1420 \mathrm{sh}$ & 1410 & $\mathrm{~A}_{\mathrm{U}}$ & $\begin{array}{l}v C 9-\mathrm{C} 14, \\
v \mathrm{C} 21-\mathrm{C} 26\end{array}$ & 1417 & A & wagCH$_{2}(\mathrm{C} 11)$ & 1426 & wagCH${ }_{2}$ \\
\hline $1408 \mathrm{sh}$ & & & & 1411 & B & wagCH ${ }_{2}(\mathrm{C} 23)$ & 1411 & wagCH${ }_{2}$ \\
\hline $1385 \mathrm{~s}$ & 1397 & $\mathrm{~A}_{\mathrm{G}}$ & wagCH ${ }_{2}(\mathrm{C} 23)$ & 1371 & B & $\beta \mathrm{C} 26-\mathrm{H} 27, \beta \mathrm{C} 21-\mathrm{H} 22$ & 1379 & $\beta \mathrm{C}-\mathrm{H}$ \\
\hline 1374 sh & 1392 & $\mathrm{~A}_{\mathrm{U}}$ & wagCH $2(\mathrm{C} 11)$ & 1360 & A & $\rho \mathrm{CH}_{2}(\mathrm{C} 11), \rho \mathrm{CH}_{2}(\mathrm{C} 23)$ & 1366 & $\rho \mathrm{CH}_{2} \beta \mathrm{C}-\mathrm{H}$ \\
\hline $1313 v s$ & 1326 & $\mathrm{~A}_{\mathrm{G}}$ & $\beta \mathrm{C} 26-\mathrm{H} 27, \beta \mathrm{C} 14-\mathrm{H} 15$ & 1325 & B & $\mathrm{v}_{\mathrm{a}} \mathrm{NO}_{2}(\mathrm{~N} 31)$ & 1333 & $\rho \mathrm{CH}_{2} \beta \mathrm{C}-\mathrm{H}$ \\
\hline $1313 v s$ & & & & 1317 & A & $v_{a} \mathrm{NO}_{2}(\mathrm{~N} 3)$ & 1324 & $v_{\mathrm{a}} \mathrm{NO}_{2} \rho \mathrm{CH}_{2}$ \\
\hline $1293 \mathrm{sh}$ & 1307 & $\mathrm{~A}_{U}$ & $\rho \mathrm{CH}_{2}(\mathrm{C} 11), \rho \mathrm{CH}_{2}(\mathrm{C} 23)$ & & & & 1291 & $\rho \mathrm{CH}_{2}$ \\
\hline $1269 \mathrm{sh}$ & 1277 & $A_{G}$ & $v_{\mathrm{s}} \mathrm{NO}_{2}(\mathrm{~N} 3)$ & & & & 1260 & $v_{\mathrm{a}} \mathrm{NO}_{2} \rho \mathrm{CH}_{2}$ \\
\hline $1261 \mathrm{sh}$ & 1274 & $\mathrm{~A}_{U}$ & $v_{\mathrm{s}} \mathrm{NO}_{2}(\mathrm{~N} 31)$ & & & & 1244 & $\rho \mathrm{CH}_{2} \beta \mathrm{C}-\mathrm{H}$ \\
\hline $1254 \mathrm{sh}$ & 1248 & $\mathrm{~A}_{\mathrm{G}}$ & $\rho \mathrm{CH}_{2}(\mathrm{C} 11), \rho \mathrm{CH}_{2}(\mathrm{C} 23)$ & 1243 & B & $\beta \mathrm{R}_{1} \mathrm{~V} \mathrm{C} 16-\mathrm{C} 11$ & 1243 & $\beta \mathrm{C}-\mathrm{H}$ \\
\hline $1240 \mathrm{sh}$ & 1232 & $\mathrm{~A}_{U}$ & vC21-C28 & 1236 & A & $\begin{array}{l}v \mathrm{C} 23-\mathrm{C} 28 \\
\text { v } 16-\mathrm{C} 11\end{array}$ & 1238 & $v \mathrm{C}-\mathrm{C}$ \\
\hline $1223 \mathrm{sh}$ & & & & 1224 & A & $\beta \mathrm{C} 14-\mathrm{H} 15$ & 1229 & $\beta \mathrm{C}-\mathrm{H}$ \\
\hline $1215 \mathrm{sh}$ & & & & 1215 & B & $\mathrm{v}_{\mathrm{a}} \mathrm{NO}_{2}(\mathrm{~N} 31)$ & 1222 & $\beta \mathrm{C}-\mathrm{H}$ \\
\hline $1203 \mathrm{sh}$ & 1210 & $\mathrm{~A}_{U}$ & $v \mathrm{C} 23-\mathrm{C} 28$ & 1210 & A & $\mathrm{v}_{\mathrm{a}} \mathrm{NO}_{2}(\mathrm{~N} 3)$ & & \\
\hline $1189 \mathrm{sh}$ & 1191 & $\mathrm{~A}_{\mathrm{G}}$ & $v \mathrm{C} 16-\mathrm{C} 11$ & & & & 1194 & $\rho \mathrm{NH}_{3}$ \\
\hline $1183 \mathrm{sh}$ & 1180 & $\mathrm{~A}_{\mathrm{G}}$ & $\beta \mathrm{C} 21-\mathrm{H} 22, \beta \mathrm{C} 9-\mathrm{H} 10$ & & & & 1193 & $\rho \mathrm{NH}_{3}$ \\
\hline $1150 \mathrm{~m}$ & 1150 & $\mathrm{~A}_{U}$ & $\rho^{\prime} \mathrm{NH}_{3}(\mathrm{~N} 5), \rho^{\prime} \mathrm{NH}_{3}(\mathrm{~N} 17)$ & 1156 & A & $v \mathrm{C} 9-\mathrm{C} 14$ & 1162 & $\rho \mathrm{NH}_{3}$ \\
\hline $1150 \mathrm{~m}$ & & & & 1153 & B & $\rho \mathrm{NH}_{3}(\mathrm{~N} 5), \rho^{\prime} \mathrm{NH}_{3}(\mathrm{~N} 5)$ & 1159 & $\beta \mathrm{C}-\mathrm{H}$ \\
\hline $1145 \mathrm{sh}$ & 1143 & $\mathrm{~A}_{\mathrm{G}}$ & $\tau \mathrm{N} 17-\mathrm{H} 18, \tau \mathrm{O} 29-\mathrm{H} 18$ & 1145 & A & $\rho^{\prime} \mathrm{NH}_{3}(\mathrm{~N} 17)$ & 1147 & $\rho \mathrm{NH}_{3}$ \\
\hline $1129 \mathrm{sh}$ & & & & & & & 1129 & $\rho \mathrm{NH}_{3}$ \\
\hline $1089 w$ & 1110 & $\mathrm{~A}_{U}$ & $\mathrm{vC} 21-\mathrm{C} 26$ & & & & & \\
\hline $1075 \mathrm{sh}$ & & & & 1072 & B & $\tau \mathrm{N} 17-\mathrm{H} 18, \tau \mathrm{N} 5-\mathrm{H} 6$ & 1076 & $\rho \mathrm{NH}_{3}$ \\
\hline & 1064 & $\mathrm{~A}_{\mathrm{G}}$ & $\tau \mathrm{N} 5-\mathrm{H} 6, \tau \mathrm{O} 1-\mathrm{H} 6$ & & & & 1065 & $v_{\mathrm{s}} \mathrm{NO}_{2}$ \\
\hline & 1062 & $\mathrm{~A}_{U}$ & $\tau \mathrm{N} 17-\mathrm{H} 18$ & & & & 1063 & $v_{\mathrm{s}} \mathrm{NO}_{2}$ \\
\hline $1050 \mathrm{w}$ & & & & 1054 & A & $\delta \mathrm{N} 5 \mathrm{H} 6 \mathrm{O} 1, \delta \mathrm{N} 17 \mathrm{H} 18 \mathrm{O} 29$ & & \\
\hline $1034 \mathrm{sh}$ & & & & 1040 & B & $\beta \mathrm{R}_{1}$ & 1044 & $v_{\mathrm{s}} \mathrm{NO}_{2}$ \\
\hline & 1018 & $A_{G}$ & $\beta \mathrm{R}_{1}$ & 1019 & B & $v_{\mathrm{s}} \mathrm{NO}_{2}(\mathrm{~N} 31), v_{\mathrm{s}} \mathrm{NO}_{2}(\mathrm{~N} 3)$ & & \\
\hline $1006 \mathrm{sh}$ & & & & 1014 & A & $v_{\mathrm{s}} \mathrm{NO}_{2}(\mathrm{~N} 31), v_{\mathrm{s}} \mathrm{NO}_{2}(\mathrm{~N} 3)$ & 1005 & $v \mathrm{~N}-\mathrm{C}$ \\
\hline $990 \mathrm{~m}$ & 997 & $\mathrm{~A}_{U}$ & $\tau \mathrm{N} 17-\mathrm{H} 18, \tau \mathrm{O} 29-\mathrm{H} 18$ & & & & 997 & $v_{\mathrm{s}} \mathrm{NO}_{2}$ \\
\hline $990 \mathrm{~m}$ & 991 & $\mathrm{~A}_{U}$ & $\tau \mathrm{N} 17-\mathrm{H} 18, \tau \mathrm{O} 29-\mathrm{H} 18$ & 981 & A & $\gamma \mathrm{C} 9-\mathrm{H} 10, \gamma \mathrm{C} 14-\mathrm{H} 15$ & 990 & $v \mathrm{~N}-\mathrm{C}$ \\
\hline $990 \mathrm{~m}$ & 979 & $A_{G}$ & $\gamma \mathrm{C} 21-\mathrm{H} 22, \gamma \mathrm{C} 9-\mathrm{H} 10$ & 978 & B & $v \mathrm{~N} 5-\mathrm{C} 11, v \mathrm{~N} 17-\mathrm{C} 23$ & 979 & $\gamma \mathrm{C}-\mathrm{H}$ \\
\hline $990 \mathrm{~m}$ & 975 & $\mathrm{~A}_{\mathrm{U}}$ & vN17-C23 & 974 & A & $\gamma \mathrm{C} 9-\mathrm{H} 10, \gamma \mathrm{C} 14-\mathrm{H} 15$ & 975 & $\gamma \mathrm{C}-\mathrm{H}$ \\
\hline \multirow[t]{2}{*}{ 970sh } & 967 & $\mathrm{~A}_{U}$ & $v \mathrm{~N} 5-\mathrm{C} 11$ & & & & 972 & $\gamma \mathrm{C}-\mathrm{H}$ \\
\hline & 962 & $A_{G}$ & vN17-C23,vN5-C11 & 956 & A & $\gamma \mathrm{C} 21-\mathrm{H} 22, \gamma \mathrm{C} 26-\mathrm{H} 27$ & 961 & $v \mathrm{~N}-\mathrm{C} \gamma \mathrm{C}-\mathrm{H}$ \\
\hline 916sh & 928 & $\mathrm{~A}_{\mathrm{G}}$ & $v \mathrm{~N} 31-\mathrm{O} 29$ & 902 & B & $\tau \mathrm{N} 17-\mathrm{H} 18, \tau \mathrm{N} 5-\mathrm{H} 6$ & 933 & $v \mathrm{~N}-\mathrm{C}$ \\
\hline 916sh & 927 & $\mathrm{~A}_{U}$ & vN3-O1 & & & & 924 & $\tau \mathrm{wCH}_{2}$ \\
\hline $896 \mathrm{~m}$ & 860 & $\mathrm{~A}_{\mathrm{G}}$ & $\tau \mathrm{wCH}_{2}(\mathrm{C} 11)$ & 893 & A & $\tau \mathrm{wCH}_{2}(\mathrm{C} 11), \tau \mathrm{wCH}_{2}(\mathrm{C} 23)$ & 884 & $\tau \mathrm{wCH}_{2}$ \\
\hline 852sh & 860 & $\mathrm{~A}_{U}$ & $\tau \mathrm{wCH}_{2}(\mathrm{C} 23)$ & 848 & B & $\gamma \mathrm{C} 9-\mathrm{H} 10, \gamma \mathrm{C} 14-\mathrm{H} 15$ & 858 & $\gamma \mathrm{C}-\mathrm{H}$ \\
\hline $849 m$ & 842 & $\mathrm{~A}_{\mathrm{G}}$ & $\begin{array}{l}\gamma \mathrm{C} 21-\mathrm{H} 22, \\
\gamma \mathrm{C} 9-\mathrm{H} 10 \\
\gamma \mathrm{C} 26-\mathrm{H} 27\end{array}$ & 837 & B & $\gamma \mathrm{C} 21-\mathrm{H} 22, \gamma \mathrm{C} 26-\mathrm{H} 27$ & 850 & $\gamma \mathrm{C}-\mathrm{H}$ \\
\hline $827 \mathrm{sh}$ & 829 & $\mathrm{~A}_{\mathrm{U}}$ & $\tau_{\mathrm{WCH}}(\mathrm{C} 11), \tau_{\mathrm{WCH}}(\mathrm{C} 23)$ & 835 & A & $\beta \mathrm{R}_{3} v \mathrm{C} 23-\mathrm{C} 28$ & 830 & wagNO ${ }_{2}$ \\
\hline 819sh & 809 & $\mathrm{~A}_{\mathrm{G}}$ & $\tau_{\mathrm{wCH}}(\mathrm{C} 11), \tau_{\mathrm{wCH}}(\mathrm{C} 23)$ & 821 & A & wagNO ${ }_{2}(\mathrm{~N} 3)$ & 825 & wagNO ${ }_{2}$ \\
\hline
\end{tabular}




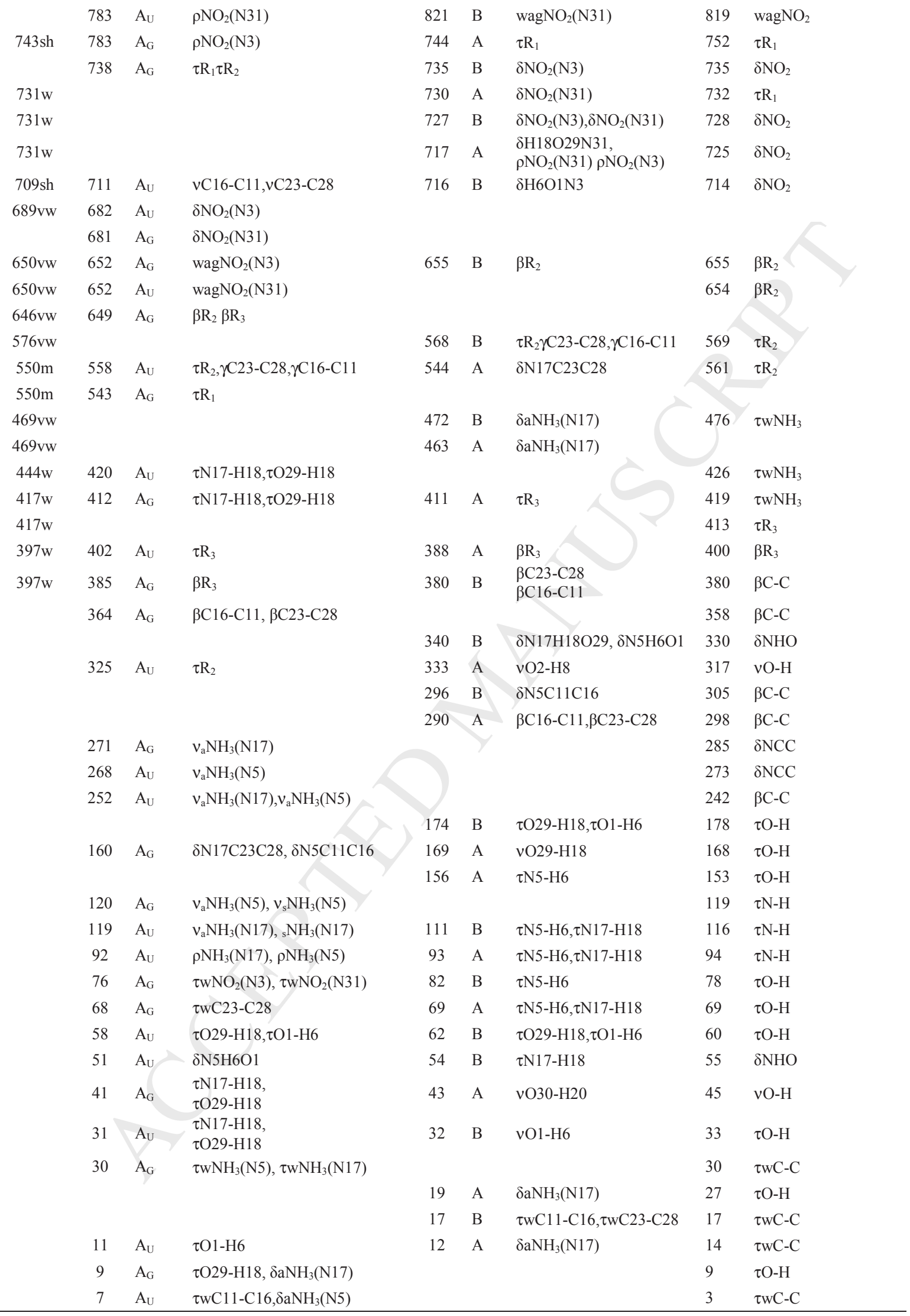

Abbreviations: $v$, stretching; $\beta$, deformation in the plane; $\gamma$, deformation out of plane; wag, wagging; $\tau$, torsion; $\beta_{\mathrm{R}}$, deformation ring $\tau_{\mathrm{R}}$, torsion ring; $\rho$, rocking; $\tau \mathrm{W}$, twisting; $\delta$, deformation; a, antisymmetric; s, symmetric; ${ }^{a}$ This work, ${ }^{b}$ From scaled quantum mechanics force field. 
Table 8. Comparison of main scaled internal force constants for $p$-xylylenediaminium bis(nitrate) considering monodentate and bidentate coordination modes for the nitrate groups compared with those reported for chromyl nitrate.

\begin{tabular}{|c|c|c|c|c|}
\hline \multicolumn{5}{|c|}{ B3LYP Method } \\
\hline & p-xylylenediamin & $\mathrm{s}(\text { nitrate })^{\mathrm{a}}$ & Chrom & $a e^{b}$ \\
\hline \multirow{2}{*}{ Force constant } & monodentate & bidentate & monodentate & bidentate \\
\hline & $6-311++\mathrm{G}^{* *}$ & $6-311 \mathrm{G}^{*}$ & $6-311++\mathrm{G}$ & $6-311++\mathrm{G}$ \\
\hline$f(v N=O)$ & 9.74 & 10.26 & 15.83 & 11.71 \\
\hline$f(v N-O)$ & 4.25 & 7.88 & 3.22 & 4.62 \\
\hline$f(v C-N)$ & 4.23 & 4.30 & & \\
\hline$f(\nu C-C)$ & 4.27 & 4.70 & & \\
\hline$f\left(v C-C_{R}\right)$ & 6.34 & 6.92 & & \\
\hline$f\left(v N-H_{3}\right)$ & 4.36 & 5.93 & & \\
\hline$f(\delta O=N=O)$ & 1.53 & & 1.58 & \\
\hline$f(\delta O-N-O)$ & & 4.47 & & \\
\hline$f(\delta O=N-O)$ & 1.58 & 1.56 & 2.09 & 1.87 \\
\hline$f(\delta N-O-H)$ & 0.89 & & & \\
\hline$f(\delta N-H-O)$ & 0.19 & & & \\
\hline
\end{tabular}

Units are mdyn $\AA^{-1}$ for stretching and mdyn $\AA \operatorname{rad}^{-2}$ for angle deformations

${ }^{\mathrm{a}}$ This work, ${ }^{\mathrm{b}}$ From Ref. [1-3] 
(a)

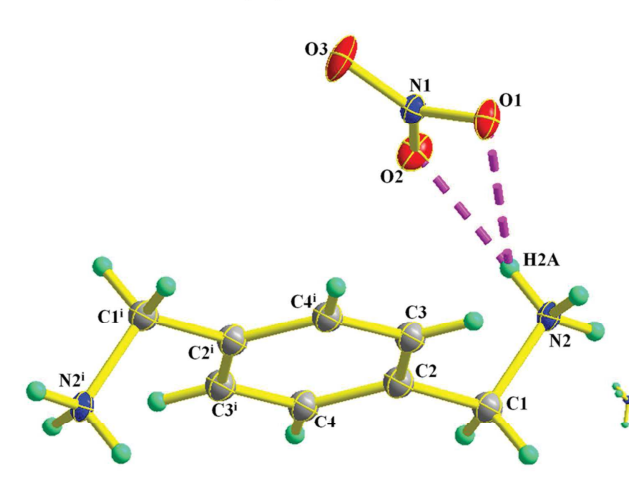

(b)

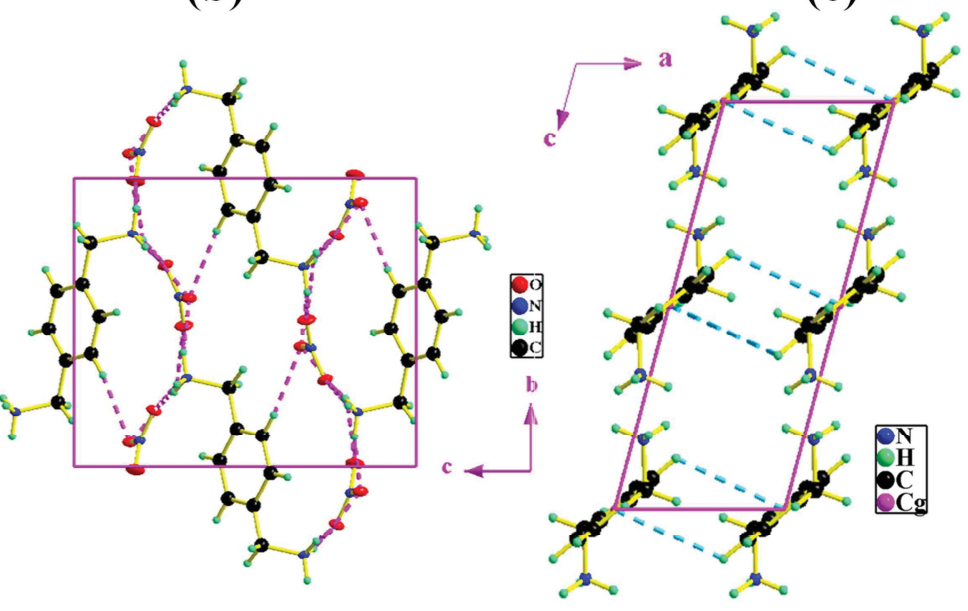

(c)

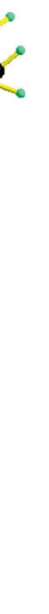




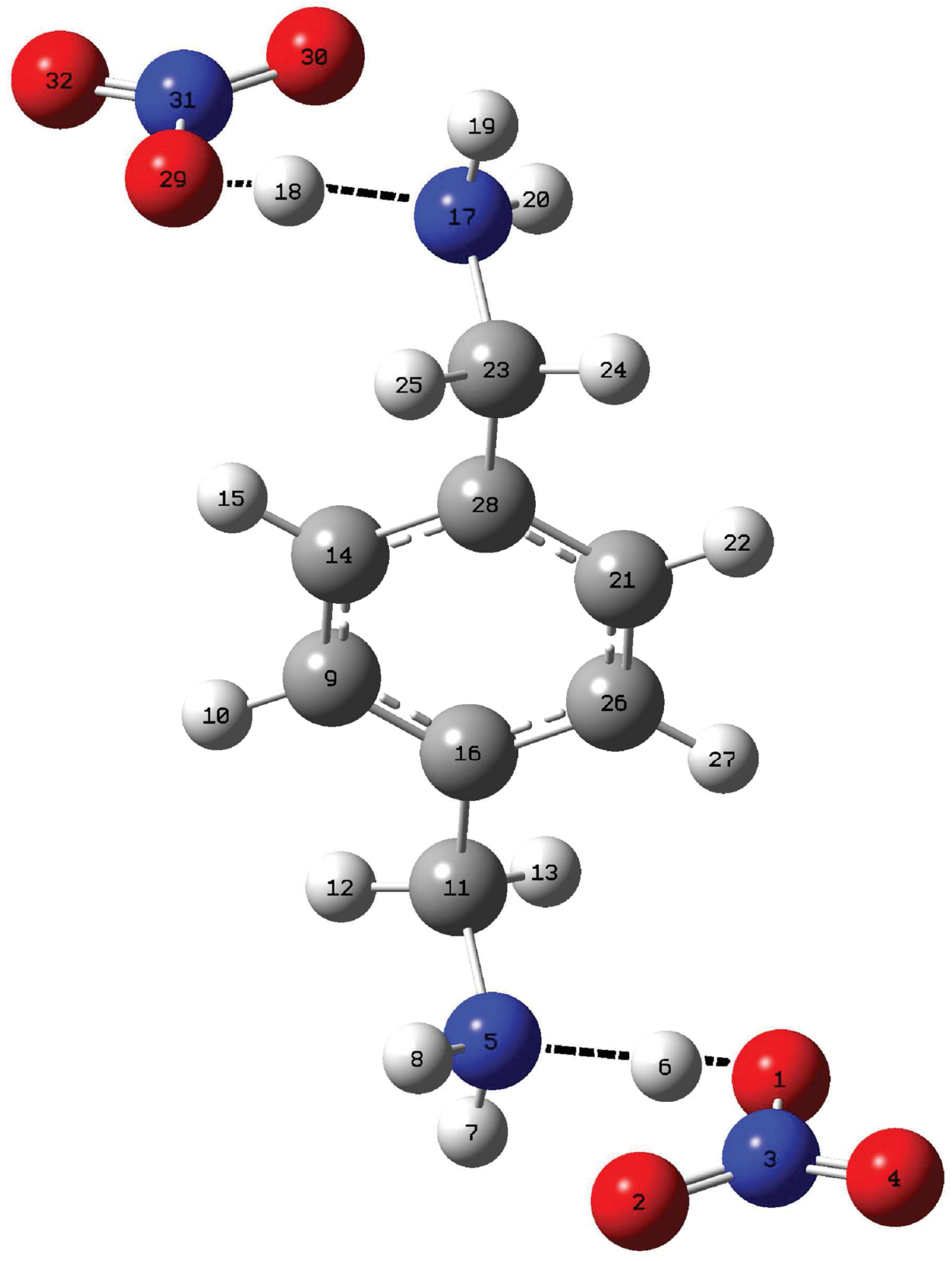




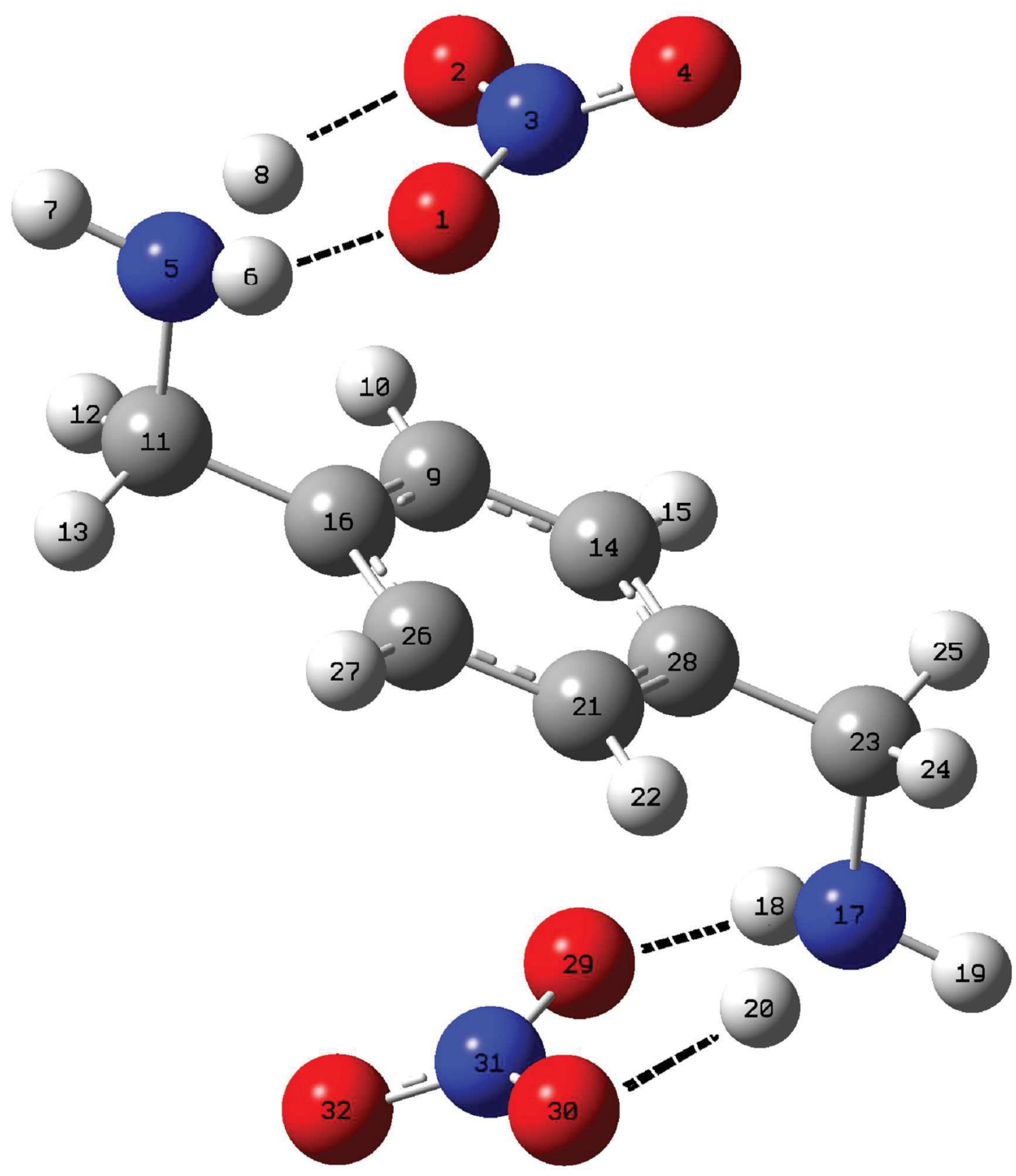




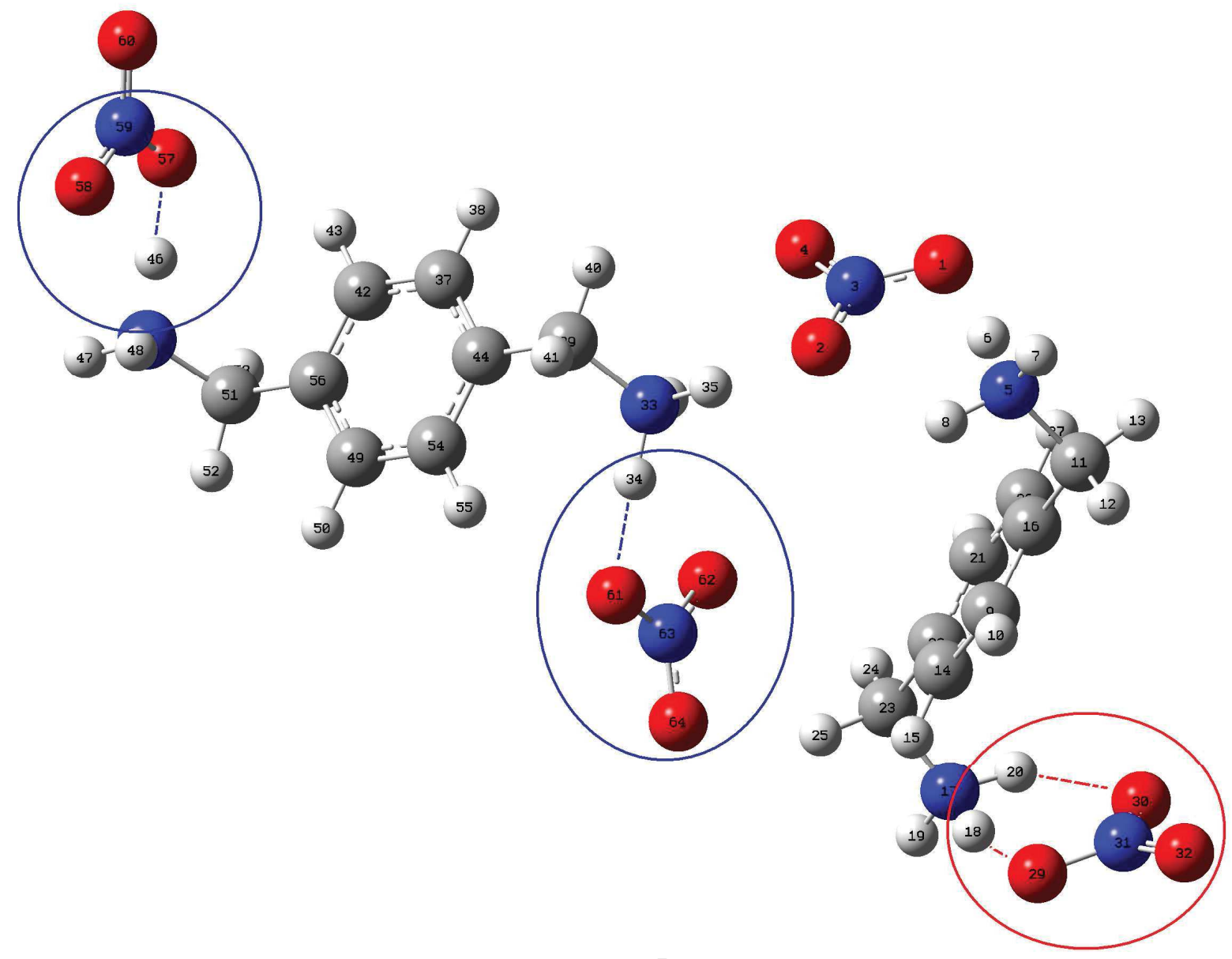




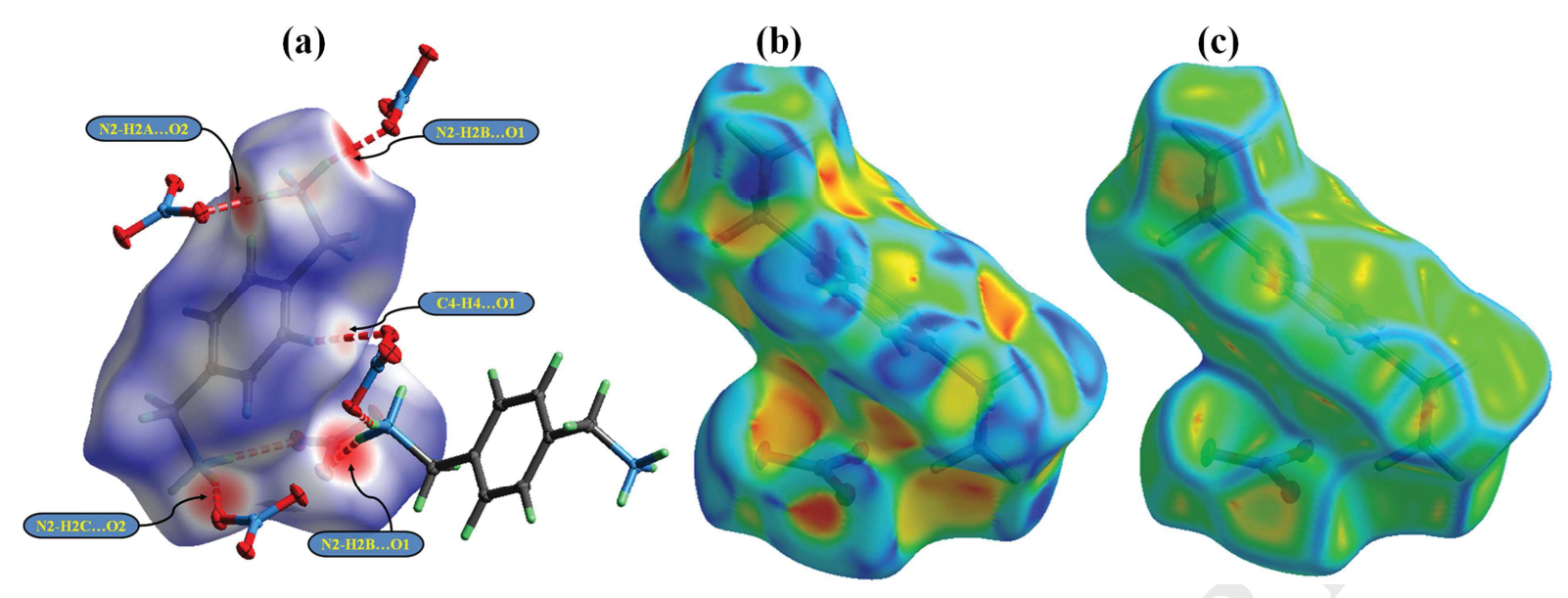




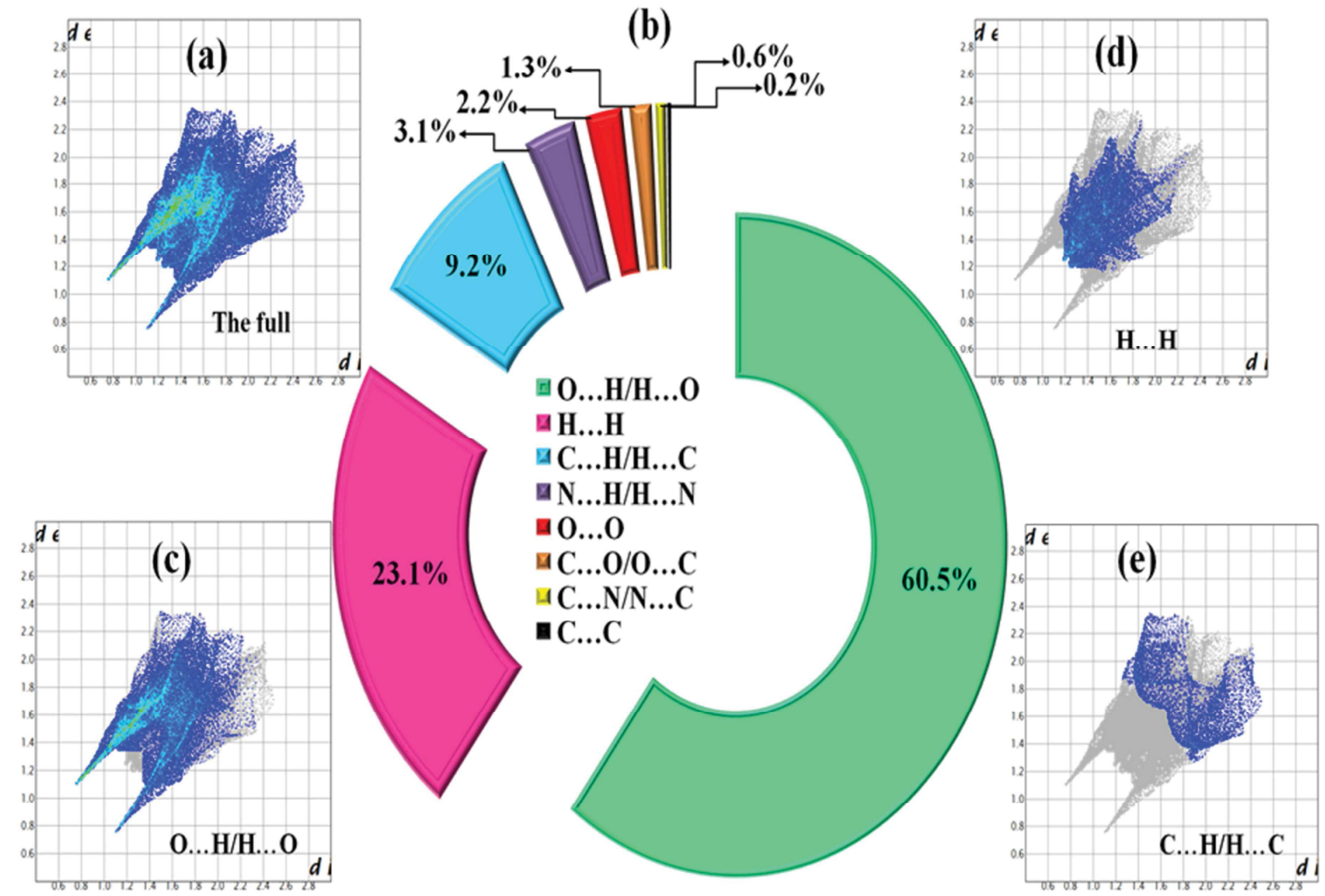




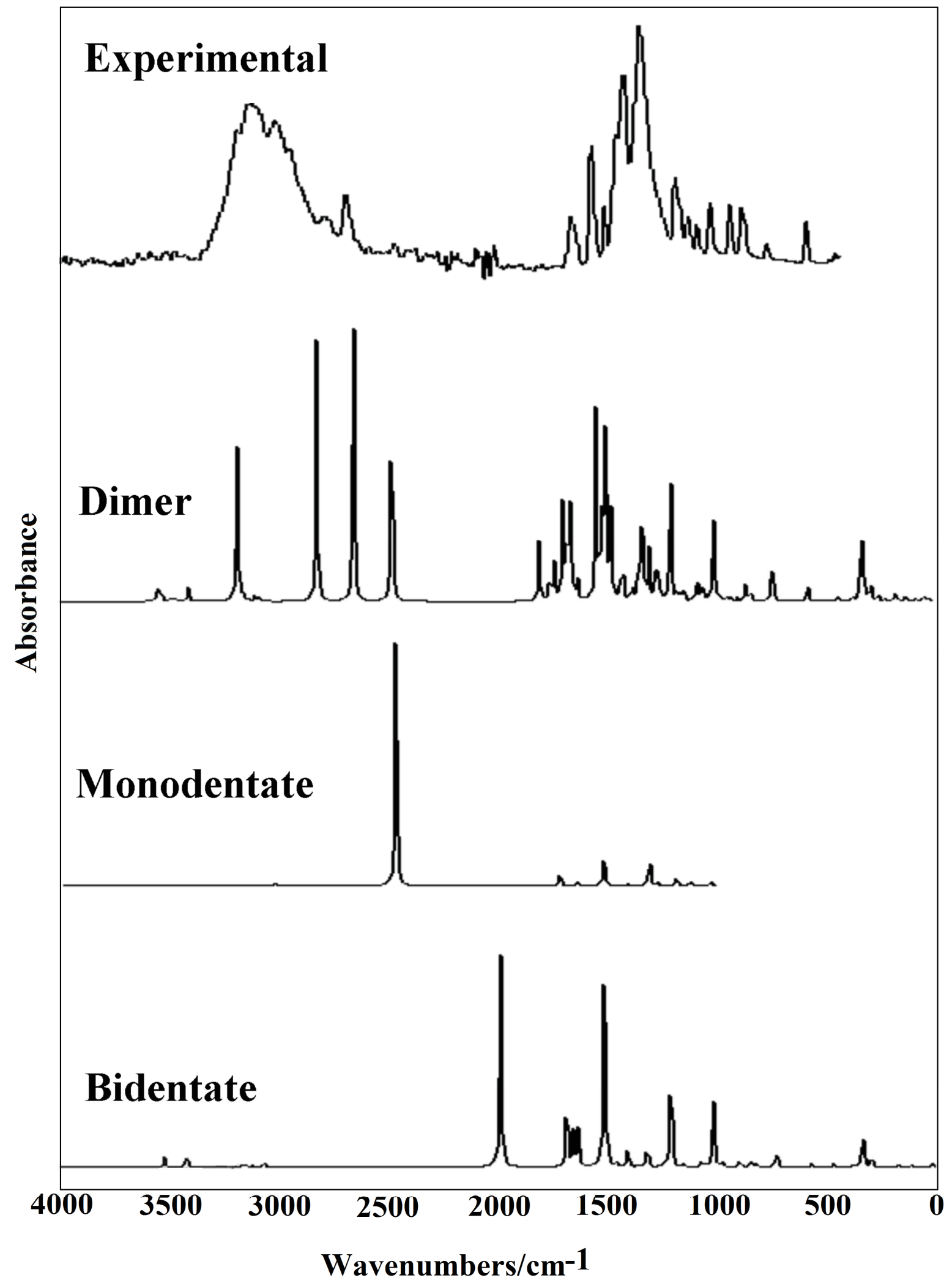




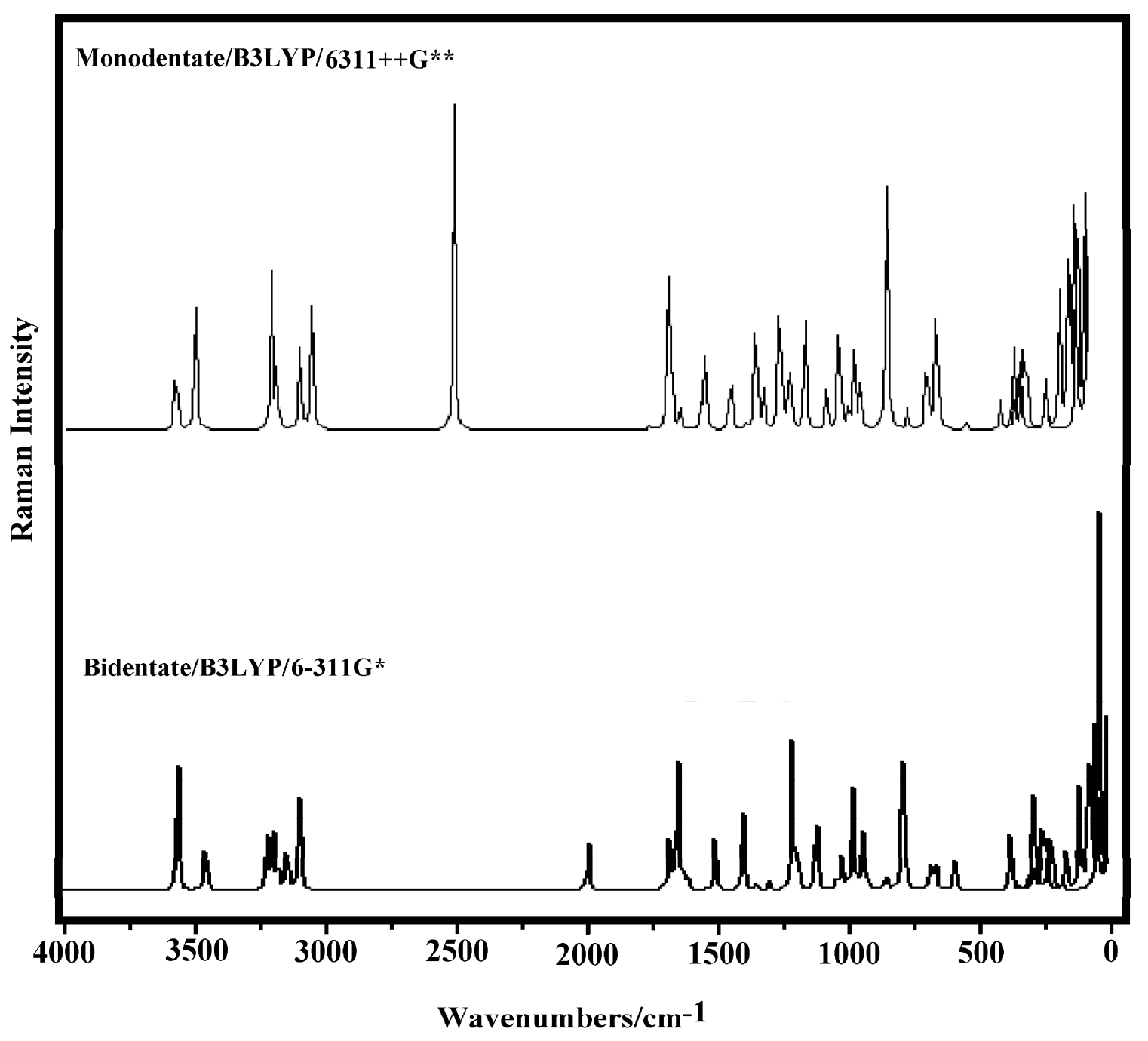




\section{H}

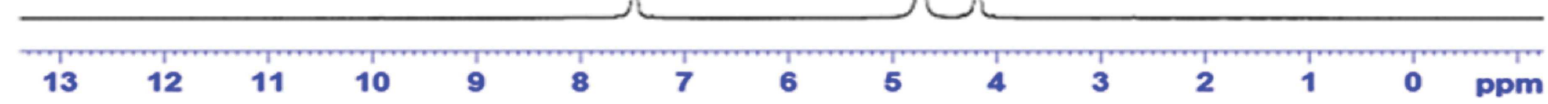

13C

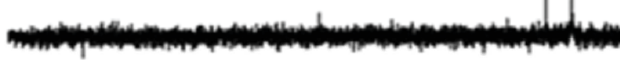

200

180

160

140

120

100

80

60

40

20

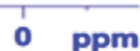




\section{Highlights}

The p-xylylenediaminium bis(nitrate) compound have been synthesized

The compound was characterized by the FTIR, UV-Visible and ${ }^{1} \mathrm{H}-$ and ${ }^{13} \mathrm{C}-\mathrm{NMR}$ spectra

The nitrate ligands were considered with monodentate and bidentate coordination modes

The IR bands at 1986/1856 $\mathrm{cm}^{-1}$ could justify the presence of the bidentate species

The bands at 2754, 2547, 1779, 1704 and $1536 \mathrm{~cm}^{-1}$ support the presence of the dimer 